(2)

(1) 


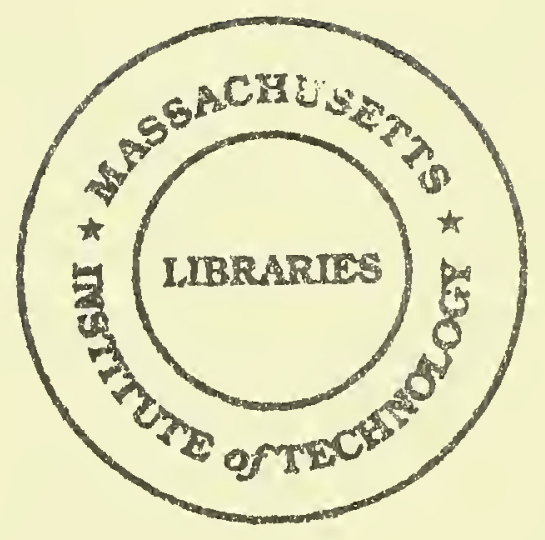


Digitized by the Internet Archive in 2011 with funding from Boston Library Consortium Member Libraries 

Massachusetts Institute of Technology

Department of Economics

Working Paper Series

\title{
The Skill Content of Recent Technological Change: An Empirical Exploration
}

\author{
David H. Autor \\ Frank Levy \\ Richard Murnane \\ Working Paper 01-22 \\ June 2001 \\ Room E52-251 \\ 50 Memorial Drive \\ Cambridge, MA 02142
}

This paper can be downloaded without charge from the Social Science Research Network Paper Collection at http://papers.ssrn.com/paper.taf?abstract id=272691 
MASSACHUSETSS INSTITUTE

OF TECHNOLOGY

AUG 152001

LIBRARIES

LIBRARIES 


\title{
Massachusetts Institute of Technology Department of Economics Working Paper Series
}

\section{The Skill Content of Recent Technological Change: An Empirical Exploration}

\author{
David H. Autor \\ Frank Levy \\ Richard Murnane \\ Working Paper $01-22$ \\ June 2001 \\ Room E52-251 \\ 50 Memorial Drive \\ Cambridge, MA 02142
}

This paper can be downloaded without charge from the Social Science Research Network Paper Collection at http://papers.ssrn.com/paper.taf?abstract id $=272691$ 


\title{
The Skill Content of Recent Technological Change: An Empirical Exploration
}

\author{
David H. Autor \\ MIT Department of Economics and NBER
}

Frank Levy

MIT Department of Urban Studies and Planning and Russell Sage Fouridation

\author{
Richard J. Murnane \\ Harvard University Graduate School of Education and NBER ${ }^{1}$
}

June 2001

Revised from January 2000

\begin{abstract}
We apply an understanding of what computers do - the execution of procedural or rules-based logic - to study how computer technology alters job skill demands. We contend that computer capital (1) substitutes for a limited and well-defined set of human activities, those involving routine (repetitive) cognitive and manual tasks; and (2) complements activities involving non-routine problem solving and interactive tasks. Provided these tasks are imperfect substitutes, our model implies measurable changes in the task content of employment, which we explore using representative data on job task requirements over 1960-1998. Computerization is associated with declining relative industry demand for routine manual and cognitive tasks and increased relative demand for non-routine cognitive tasks. Shifts are evident within detailed industries, within detailed occupations, and within education groups within industries. Translating observed task shifts into educational demands, the sum of within-industry and within-occupation task changes explains thirty to forty percent of the observed relative demand shift favoring college versus noncollege labor during 1970 to 1998, with the largest impact felt after 1980. Changes in task content within nominally identical occupations explain more than half of the overall demand shift induced by computerization.
\end{abstract}

JEL: O30, J23, J31, E23

\footnotetext{
${ }^{1}$ We thank the Alfred P. Sloan Foundation, the Russell Sage Foundation and the MIT-Ford Research Collaboration for financial support and Kokkeong Puah, Detelina Vasileva, and especially Melissa Schettini for excellent research assistance. We are indebted to Daron Acemoglu, Eli Berman, Lex Borghans, Lawrence Katz, Kevin Lang, Thomas Lemieux, Sendhil Mullainathan, Kathryn Shaw and Bas Ter Weel for valuable suggestions. Thanks go to Randy Davis of MIT's Artificial Intelligence Laboratory and Pete Szolovits of MIT's Laboratory for Computer Science for clarifying issues in artificial intelligence. We are grateful to Michael Handel for providing access to key data sources and for expert advice on using the Dictionary of Occupational Titles. The usual disclaimer about responsibility for errors deserves special emphasis here.
} 


\section{Introduction}

Much quantitative and case-study evidence documents a strong association between the adoption of computers and computer-based technologies and the increased use of college-educated and nonproduction labor within detailed industries, within firms, and across plants within industries. These patterns implicating computerization as a potential source of a demand shift favoring better-educated labor appear consistently in studies from the U.S., the OECD, Canada and other developed and developing countries. ${ }^{1}$ While the empirical relationship between computer investment and use of educated labor is firmly established, it is our view that the conceptual link explaining specifically how computer technology complements skilled labor or substitutes for unskilled labor is not well

developed. In particular, most studies do not ask, or are prevented by data limitations from answering, what is it that computers do - or what is it that people do with computers - that causes educated workers to be relatively more in demand. ${ }^{2}$

These mechanisms may.initially appear trivial; computers substitute for less educated workers in the performance of simple tasks or and/or complement the performance of more educated workers in complex tasks. Reflection suggests that the relationship between human education and "computer skills" is more complex. In the economy of the 1970s, long haul truck driving and double entry bookkeeping were both tasks routinely performed by workers with modest education, typically high school graduates. In the present economy, computers perform a vast share of the routine bookkeeping via database and accounting software but do little of the truck driving. Similarly, playing a strong game

\footnotetext{
${ }^{1}$ Autor, Katz and Krueger (1998) and Berman, Bound and Griliches (1994) present evidence on industry level shifts. Bresnahan, Brynjolfsson and Hitt (forthcoming) and Levy and Murnane (1996) and Doms, Dunne and Troske (1997) provide evidence on firm and plant level shifts. Machin and Van Reenen (1998) provide data on the OECD, Gera, Gu and Lin (2001) on Canada, and Berman, Bound and Machin (1998) and Berman and Machin (2000) on other developing and developed countries.

${ }^{2}$ Herbert Simon (1960) provides the first treatment of this question with which we are familiar. His essay introduces many of the ideas explored here. Influential studies in the ethnography of work literature provide insightful discussions of what computers and related technology do in the workplace but do not consider economic implications (Adler, 1986; Orr, 1996; and Zuboff, 1988). Bresnahan (1999), Bresnahan, Brynjolfsson and Hitt (forthcoming), Goldin and Katz (1998), and Lindbeck and Snower (2000) exemplify important studies in the economic literature that explore why new technologies and educated labor appear to be relative complements.
} 
of chess and writing a persuasive legal brief are both skilled tasks. Current computer technology can readily perform the first task but not the second. These examples suggest that neither all 'high' nor all 'low' skilled tasks are equally amenable to computerization. We argue below that present computer technology has quite specific applications and limitations that make it an incomplete substitute for both well-educated and less educated human labor.

The objective of this paper is to propose and test a model of how the computerization of workplace tasks alters job content and thereby human skill demands. We build the model from an understanding of what computers do - by which we mean the tasks that present computer technology is particularly suited to performing. By conceptualizing and measuring job skill demands in terms of job tasks rather than the edncational credentials of workers performing those tasks, we believe our analysis makes three contributions. First, we provide an explicit account of how computerization alters work content, exposing the mechanisms undergirding the widely documented observation that computers and education are relative complements. Second, using representative observational metrics of job tasks from the Dictionary of Occupational Titles (DOT), we analyze the degree to which technological change has altered the cognitive and manual content of jobs between 1960 and 1998. A unique virtue of the DOT is that it permits us to study changes in job content within industries, education groups, and occupations - phenomena that in all but the first case are not normally observable. Finally, we quantify the extent to which changes in the structure of work induced by computerization have contributed to recent observed increases in the relative demand for educated labor. We find that this contribution is sizable.

Our analysis builds upon two branches of the literature on the demand for skill. The first infers shifts in the demand for skills from secular trends in the occupational, educational, and gender composition of employment. ${ }^{3}$ The second posits, and in several cases tests empirically, individual and

\footnotetext{
${ }^{3}$ See Bound and Johnson (1992); Juhn (1999), Juhn, Murphy and Pierce (1993), Katz and Murphy (1992), Murphy and Welch (1992 and 1993), and Welch (2000).
} 
organizational level complementarities between technological change and workers' learning and problem solving capabilities. ${ }^{4}$ Our analysis extends both avenues of research. We first offer a conceptual framework that makes specific predictions about complementarity and substitutability between new technology and labor in carrying out workplace tasks. We next explore the empirical implications of this framework using economy-wide data on the task distribution of employment over four decades.

\section{Framework}

For purposes of our framework, it is useful to conceptualize a job as a series of tasks: moving an object, executing a calculation, communicating a piece of information, resolving a discrepancy. In this context, we ask the question: which tasks can be performed by a computer? ${ }^{5}$ A good first answer is that computers perform tasks that can be expressed using procedural or 'rules-based' logic, that is codified in a fully specified sequence of logical programming commands ("If-Then-Do" statements) that designate unambiguously what actions the machine will perform and in what sequence at each contingency to achieve the desired result. ${ }^{6}$ The simple observation that tasks cannot be computerized unless they can be proceduralized is the point of departure for our discussion. We focus first on the computerization of manual tasks and subsequently discuss information processing (cognitive) tasks. ${ }^{7}$

\footnotetext{
${ }^{4}$ Important examples include Acemoglu (1999), Bartel and Lichtenberg (1989), Bresnahan (1999), Bresnahan, Brynjolfsson and Hitt (forthcoming), Casselli (1999), Goldin and Katz (1998), Lindbeck and Snower (2000), Nelson and Phelps (1966), Schultz (1975), and Welch (1970).

${ }^{5}$ We take as given that the rapidly declining price of computer capital - a 35 percent average annual rate from 1985 to 1996 (Grimm, 1998) - provides firms with strong incentives to answer this question. Jorgenson and Stiroh (1995 and 1999) discuss the importance of the declining price of computer capital in inducing substitution between information technology and other forms of capital and labor input. The model advanced by Borghans and Ter Weel (2000) underscores that computers are particularly likely to substitute for (in our terminology) routine tasks performed by high-wage workers.

${ }^{6}$ The Encyclopedia Brittanica (2000) defines a computer program as a "detailed plan or procedure for solving a problem with a computer; more specifically, an unambiguous, ordered sequence of computational instructions necessary to achieve such a solution."

${ }^{7}$ A logical question is whether the requirement for proceduralization is intrinsic to computer technology or is an artifact of the economic incentives that shaped its development. Our view is that proceduralization is inherent, although other specific aspects of computer technology may not be. As evidence for this point, we note that Charles Babbage articulated the notion of procedural programming in his description of the "Analytical Engine" in 1837 , almost a century before the first computer was developed (cf. Babbage, 1888). Babbage's device was in turn inspired by what many consider to be the first mechanical computer, the Jacquard Loom developed by Joseph Marie Jacquard
} 
Many manual tasks that humans perform (or used to perform) at their jobs can be specified in straightforward computer code and accomplished by machines, for example, monitoring the temperature of a steel finishing line or moving a windshield into place on an assembly line. However, a problem that arises with many tasks is that, as Michael Polanyi (1966) put it, "we do not know how to do many of the things we do." Accordingly, it is difficult to develop machines that carry out these tasks. For example, it is a trivial undertaking for a human child to walk on two legs across a room to pick an apple from a bowl of fruit. This same task is presently a daunting challenge for computer science and robotics. Both optical recognition of objects in a visual field and bipedal locomotion across an uneven surface appear to require enormously sophisticated algorithms, the one in optics and the other in mechanics, which are currently poorly understood by cognitive science (Pinker, 1997). These same problems explain the earlier mentioned inability of computers to perform the tasks of long haul truckers. ${ }^{8}$

In this paper we refer to such tasks requiring visual and manual skills as 'non-routine manual activities.' We emphasize the phrase non-routine because if a manual task is sufficiently well specified or performed in a well-controlled environment, it often can be automated despite the seeming need for visual or manual skills that at present are poorly simulated by machines (as, for example, in the case of industrial robots on assembly lines). It is this 'routineness' or predictability that is lacking in the truck-

in 1801 (Mokyr, 1990). What the Jacquard loom shares with essentially all computers is: first, it is a symbolic processor, acting upon symbolic representation of information such as binary numbers or, in this case, punched cards; and, second, its actions are deterministically specified by explicit procedures or programs. Despite the substantial time interval between initial vision and ultimate implementation, the modern computer is a close relative of Babbage's machine. As Acemoglu (1998 and 2000) argues forcefully, however, the specific characteristics and applications of the technology are likely to be endogenously shaped by market forces.

${ }^{8} \mathrm{It}$ is of course a fallacy to assume that a computer must reproduce all of the runctions of a human to perform a task traditionally done by humans. Automatic Teller Machines, for example, have supplanted many bank teller functions although they cannot verify signatures or make polite conversation while tallying change. This observation raises the important question of which if any attributes of a task are intrinsic and which are artifactual characteristics that these tasks may have obtained precisely because humans traditionally performed them. Although we do not attempt to address this question here, we surmise that whether the characteristics of a task are intrinsic or merely artifactual, these historical characteristics generate real costs when automating a task. For example, if robotic technology had preceded the automobile, it is likely that vehicle navigation would have been designed to rely less heavily on sightedness. Given the present (sunk) infrastructure of sight-dependent vehicles and visually cued roads, a major cost of automating the 
driving example. ${ }^{9}$

The substitution of machinery for repetitive human labor has of course been a central thrust of technological change since (at least) the industrial revolution (cf., Hounshell, 1985; Mokyr, 1990; and Goldin and Katz, 1998). What computer capital uniquely contributes to this process is the capability to perform symbolic processing, that is, to calculate, store, retrieve, sort, and act upon information. ${ }^{10}$ Although symbolic processing depends on little more than Boolean algebra, the remarkable generality of this tool allows computers to supplant or augment human cognition in a vast range of information processing tasks that had historically been the mind's exclusive dominion. In economic terms, advances in information technology have sharply lowered the price of accomplishing procedural cognitive tasks (i.e., rules-based reasoning). Accordingly, computers increasingly substitute for the routine information processing, communications, and coordinating functions performed by clerks, cashiers, telephone operators, bank tellers, bookkeepers, and other handlers of repetitive information processing tasks, a point emphasized by Bresnahan (1999). ${ }^{11}$

Yet, the applicability of computer capital is nevertheless circumscribed by the need for an unambiguous, ordered sequence of computational instructions that specify how to achieve a desired end. As a result, there is little computer technology that can develop, test, and draw inferences from models, solve new problems, or form persuasive arguments - tasks that many jobs require. ${ }^{12}$ In the

task of driving appears to be developing computers that can perform visual processing approximately as well as humans.

${ }^{9}$ Industrial robots may, for example, select distinct parts from bins, transport parts to work stations on demand, and perform other non-repetitive manual tasks that require responding appropriately to environmental stimuli. What makes these robotic feats possible is the extreme predictability of the assembly line, a purposefully engineered attribute. As Simon (1960) observed, environmental control is a substitute for flexibility. Moreover, the simple distinction between computer-substitutable and non-substitutable tasks is not absolute. For example, by calculating more efficient long haul trucking routes, computers can 'substitute' for the labor input of long haul truck drivers without driving trucks. This observation suggests that there is a non-zero elasticity of substitution between routine and non-routine tasks, a point we encapsulate in our model.

${ }^{10}$ This point is emphasized by Weizenbaum (1976) and Bryjolfsson and Hitt (2000).

${ }^{11}$ Autor, Levy, and Murnane (2001) provide an example of this generalization in a study of the automation of check clearing in a large bank.

${ }^{12}$ Software that recognizes ill structured patterns ('neural networks') and solves problems based upon inductive reasoning from well-specified models ('model based reasoning') is under development and has been applied commercially in several cases. But these technologies have had little role in the computer-induced technical change of 
words of artificial intelligence pioneer Patrick Winston (1999):

"The goal of understanding intelligence, from a computational point of view, remains elusive. Reasoning programs still exhibit little or no common sense. Today's language programs translate simple sentences into database queries, but those language programs are derailed by idioms, metaphors, convoluted syntax, or ungrammatical expressions. Today's vision programs recognize engineered objects, but those vision programs are easily derailed by faces, trees, and mountains."

The capabilities and limitations of present computer technology make it, in our terminology, more substitutable for routine than non-routine tasks. By implication, computers are relative complements to workers engaged in non-routine tasks. This complementarity flows through three channels.

First, at a mechanical level, computers increase the share of human labor input devoted to nonroutine cognitive tasks by offloading routine manual and cognitive tasks from expensive professionals. More substantively, an outward shift in the supply of routine informational inputs (both in quantity and quality) increases the marginal productivity of workers performing non-routine tasks that rely on these inputs. For example, comprehensive bibliographic searches increase the quality of legal research; timely market information improves the efficiency of managerial decision-making; richer customer demographics increase the productivity of salespersons, etc. Third, and perhaps most significantly, workplace computerization appears to increase the demand for problem-solving tasks - a non-routine cognitive task by our definition. Because 'solved' problems are intrinsically routine and hence readily computerized, the comparative advantage of labor in a computerized environment is specifically in handling non-routine problems such as resolving production deficiencies, handling discrepancies and exceptions, and detecting and resolving unanticipated bottlenecks. ${ }^{13}$ In net, these arguments imply that price declines in computerization should augment the productivity of workers engaged in non-routine cognitive tasks.

the last three decades. See Davis (1984) for further discussion. Bresnahan (1999) similarly emphasizes that computers are at best a limited substitute for human decision-making. Levy et al. (1999) provide a discussion of rules-based reasoning in the context of auto repair.

${ }^{13}$ Observational studies that offer this insight include Adler (1986), Autor, Levy and Murnane (2001), Bartel, Ichniowski and Shaw (2000), Fernandez (1999), Levy and Murnane (1996) and Zuboff (1988). 
Table 1 provides examples of jobs in each cell of our two-by-two matrix of workplace tasks (routine versus non-routine, manual versus information processing) and states our hypothesis about the impact of computerization on the tasks in each cell. Although we limit our focus here to task shifts within occupations, these forces are likely to alter the task and organizational structure of firms along analogous dimensions. ${ }^{14}$

\section{Routine and non-routine skills in production: A model}

The manner in which an exogenous decline in the price of carrying out 'routine' tasks alters the task content of jobs and the wages attached to them depends on the elasticity of substitution between routine and non-routine tasks and the supplies of workers and capital to each. While these parameters are not known with any precision, we believe our discussion motivates several plausible assumptions. First, we have argued above that computer capital is more substitutable for humans in carrying out routine tasks than non-routine tasks. Second, we believe it is non-controversial that routine and nonroutine tasks are themselves imperfect substitutes. Third, at least in the domain of cognitive tasks, we observe that greater intensivity of routine inputs increases the marginal productivity of non-routine inputs. $^{15}$

These assumptions structure the production side of our model. Consider the following production function in which two types of tasks, routine $R$ and non-routine $N$, are used to produce output, $q$, which sells at price one. For tractability, we assume a constant returns to scale Cobb-Douglas technology:

$$
q=R^{1-\beta} N^{\beta}, \beta \in(0,1) .
$$

To encapsulate the notion that computers are more substitutable for routine than non-routine tasks, we

\footnotetext{
${ }^{14}$ See Autor, Levy and Murnane (2001), Bartel, Ichniowski and Shaw (2000), Bresnahan (1999), Bresnahan, Brynjolfsson and Hitt (1999), and Brynjolfsson and Hitt (2000), Caroli and Van Reencn (forthcoming), Garicano (2000), Lindbeck and Snower (2000), and Thesmar and Thoenig (2000) for perspectives on these ideas.

${ }^{15}$ While in the model below we aggregate our four tasks groups into only two categories - routine and non-routine we suspect that in actuality routine and non-routine manual tasks are substantially less complementary as productive inputs than are routine and non-routine cognitjve tasks.
} 
assume that computer capital, $C$, and humans are perfect substitutes in carrying out routine tasks, $R$. While this assumption is obviously extreme, the only substantive requirement for our model is that computer capital is more substitutable for humans in carrying out routine than non-routine tasks. ${ }^{16}$ Computer capital is supplied perfectly elastically at market price $P$ per efficiency unit, where $P$ is falling exogenously with time due to technical advances. The declining price of computer capital is the causal force in our model.

To model labor supply, we assume as in Roy (1951) that workers choose among occupations (here, routine and non-routine) according to comparative advantage. We model each worker as possessing a productivity endowment, $E\left(R_{i}, N_{i}\right)$, in routine and non-routine tasks specified in efficiency units where $R_{i}, N_{i}>0 \forall i$. Define the relative efficiency of individual (i) at non-routine versus routine tasks as $\alpha_{i}=N_{i} / R_{i}$ where $\alpha \in(0, \infty)$. We assume a large number of workers who choose to supply either $R_{i}$ efficiency units of routine task input or $N_{i}$ efficiency units of non-routine task input. In keeping with our discussion, we think of the decision to supply labor to routine or non-routine tasks as the choice of an occupation.

Under these assumptions, it is straightforward to trace out the implications of a technical advance a fall in the price of computer capital - for occupational choice, marginal task productivity, and wages (specified in efficiency units). Given the perfect substitutability of computer capital and routine skills, the wage per efficiency unit of routine labor is given by

$$
W_{R}=P \text {. }
$$

Since vorkers choose their occupation - that is, to supply routine or non-routine labor - to maximize earnings, the marginal worker with relative efficiency units $\alpha^{*}$ in routine vs. non-routine tasks is indifferent between routine and non-routine occupations when

\footnotetext{
${ }^{16}$ Cobb-Douglas technology implies that the elasticity of substitution between routine and non-routine tasks is one. Hence, computer capital and non-routine task inputs are relative complements.
} 
(3) $\quad \alpha^{*}=\frac{W_{R}}{W_{N}}$

Equation (3) implies that for $\alpha_{i}<\alpha^{*}$, individual $i$ supplies routine labor, and for $\alpha_{i} \geq \alpha^{*}, i$ supplies non-routine labor.

To quantify factor supplies to each occupation as a function of $\alpha^{*}$, denote the functions $g(\alpha), h(\alpha)$ that give the population endowment in efficiency units of routine and non-routine tasks respectively for each value of $\alpha$. We make no assumption on the population distribution of endowments or their correlation except to require that the joint distribution of $R_{i}, N_{i}$ is non-degenerate and has mass at all $\alpha .{ }^{17}$ Hence, we have $g(\alpha), h(\alpha)>0 \forall \alpha>0$; for every $\alpha$, there is a non-zero set of workers with total routine efficiency endowment $g(\alpha)$ and non-routine efficiency endowment $h(\alpha)$. Accordingly, both occupations face a strictly upward sloping supply of task input.

Productive efficiency requires that factors are paid their marginal products:

$$
W_{R}=\frac{\partial q}{\partial R}=(1-\beta) \theta^{-\beta} \text { and } W_{N}=\frac{\partial q}{\partial N}=\beta \theta^{1-\beta}
$$

where $\theta=\frac{C^{*}+\int_{0}^{\alpha^{*}} g(x) d x}{\int_{\alpha^{*}}^{\infty} h(x) d x}$ is the ratio of routine to non-routine task input in production. $\theta$ is a crucial endogenous variable in our model. Factors that raise the relative intensity of routine task input (that is, increase $\theta$ ) lower the wage per efficiency unit of routine task input, and vice versa for the wage paid to non-routine task input.

To evaluate the impact of a decline in the price of computer capital on the relative intensity of task input, we use (2) and the first order condition for $W_{R}$ and take logarithms to obtain

$$
\frac{\partial \ln W_{R}}{\partial \ln P}=1=-\beta \frac{\partial \ln \theta}{\partial \ln P} \Rightarrow \frac{\partial \ln \theta}{\partial \ln P}=-\frac{1}{\beta}
$$


A decline in the price of computer capital reduces the wage per efficiency unit of routine tasks and, as the final term of (5) indicates, increases the relative intensity of routine task input in production.

Since routine and non-routine tasks are complementary inputs (specifically, q-complements), increased intensity of routine task input raises the wage per efficiency unit of non-routine task input:

$$
\frac{\partial \ln W_{N}}{\partial \ln P}=\frac{\beta-1}{\beta}
$$

A decline in the price of computing power unambiguously increases the marginal productivity of workers engaged in non-routine tasks.

In the equations above, wages are specified in efficiency units. Since efficiency units vary over the population and workers choose their occupation to maximize earnings, a decline in the price of computer capital alters occupational choice. Consider the impact of a price decline in computer capital on $\alpha^{*}$, the relative efficiency endowment of the marginal worker in the routine occupation. Combining (3), (5) and (6), we find

$$
\frac{\partial \ln \alpha^{*}}{\partial \ln P}=\frac{1}{\beta}
$$

A fall in the price of computer capital decreases labor supply to the routine occupation and raises labor supply to the non-routine occupation.

Since we derived above that a decline in the price of computer capital raises the relative intensity of routine task input (i.e., $\partial \ln \theta / \partial \ln P<0$ ), (7) further implies that

$$
\frac{\partial \ln C^{*}}{\partial \ln P}<\frac{-\partial \ln \int_{0^{\alpha}}^{\alpha^{*}} g(x) d x}{\partial \ln \alpha^{*}} \cdot \frac{\partial \ln \alpha^{*}}{\partial \ln P}<0 .
$$

Although labor supply to the routine occupation declines, there is a more than offsetting increase in the demand for routine tasks in the form of computer capital. Thus, the relative intensity of routine task

\footnotetext{
${ }^{17}$ Formally, write the probability density function of relative efficiency endowments as $f(\alpha)$, with $f(0)=0$ and $f(\alpha)>0$ for $\alpha \in(0, \infty)$.
} 
input rises even as the relative labor supply of routine task input falls.

The implications for observed wages are ambiguous, however, without further assumptions.

Because an increase in non-routine relative wages may reduce the average productivity (in efficiency units) of workers entering the non-routine occupation, quality change could reduce observed wages even as the per-unit price of non-routine tasks rises. ${ }^{18}$

To summarize our simple conceptual framework, we find that a decline in the price of computer capital lowers the wages of workers carrying out routine tasks and causes employment in these tasks to contract. Although the demand for routine task input increases as the price of computer capital falls, this demand is satisfied by substitution of computer capital for human labor. Because greater relative intensity of routine task input raises the marginal productivity of non-routine tasks, the wage per efficiency unit of non-routine labor input rises.

Many of the details of our model were chosen for simplicity and are not essential to the basic results. What is critical is our assumption that computer capital is more substitutable for routine than non-routine skills, an assumption that we believe is justified by the present state of computer technology. One dimension of the model we have not explored here is how consumer tastes interact with price declines and accompanying income gains to shape final demand. If we consider the model above to characterize production in a single industry and assume that industries have heterogeneous production technologies, it is plausible, depending on elasticities, that changes in final demand could amplify or offset changes in industry level demand for skills. For this reason, we focus our empirical exploration below on the composition of demand at the industry level. ${ }^{19}$

\section{Empirical Implementation}

\footnotetext{
${ }^{18}$ For example, if there is a strictly positive correlation between workers' ability at carrying out routine and nonroutine tasks, a decline in the price of computer capital reduces average ability (in efficiency units) in both occupations. Given the decline in $W_{R} / W_{N}$, observed wages in the routine occupation unambiguously fall. But wages in the non-routine occupation may not rise.

${ }^{19}$ Mobius (2000) and Thesmar and Thoenig (2000) provide insightful formal treatments of the impact of technological change on tastes, market structure, and the implications for the organization of production.
} 
The approach of this paper is to conceptualize jobs in terms of their component tasks rather than the educational attainments of jobholders. To implement this approach, we require measures of tasks performed in particular jobs and their changes over time. We draw on information from the Fourth (1977) Edition and Revised Fourth (1991) edition of the U.S. Department of Labor's Dictionary of Occupational Titles. Many of the details of our data construction are provided in the Data Appendix. Here we discuss the features most salient to our analysis.

The U.S. Department of Labor released the first edition of the DOT in 1939 to "furnish public employment offices... with information and techniques [to] facilitate proper classification and placement of work seekers. ${ }^{, 20}$ Although the DOT was updated four times in the ensuing five decades (1949, 1965, 1977 and 1991), its structure has been little altered. Based upon first-hand observations of workplaces, DOT examiners using guidelines supplied by the Handbook For Analyzing Jobs rate occupations along 44 objective and subjective dimensions including training times, physical demands, and required worker aptitudes, temperaments, and interests. While the Dictionary of Occupational Titles categorizes more than 12 thousand highly detailed occupations, the DOT data we employ here are based on an aggregation of these detailed occupations into three-digit Census Occupation Codes (COC) of which there are approximately $4500^{21}$

Using these COC-DOT aggregations, we append DOT occupation characteristics to the Census IPUMS one percent extracts for 1960, 1970, 1980 and 1990, and to CPS Merged Outgoing Rotation Group (MORG) files for 1980, 1990 and 1998. We use all observations on non-institutionalized, employed workers, ages $18-64$. For our industry analysis, these individual worker observations are aggregated to the level of 140 consistent Census industries spanning all sectors of the economy to provide indicators of average task requirements by industry for 1960, 1970, 1980, 1990 and 1998. All individual and industry level analyses are performed using as weights full-time equivalent hours of

\footnotetext{
${ }^{20}$ U.S. Department of Labor (1939:xi) as quoted in Miller et al (1980).

${ }^{21}$ The actual number varies by Census year.
} 
labor supply, which is the product of the individual Census or CPS sampling weight times hours of work in the sample reference week and, for Census samples, weeks of work in the previous year. ${ }^{22}$

In measuring changes in task requirements, we exploit two sources of variation. The first consists of changes over time in the occupational distribution of employment economy-wide, within industries, and within-education groups within industries, holding task content within occupations at its DOT 1977 level. We refer to this source of variation as the 'extensive' (i.e., across occupations) margin, which we are able to measure consistently over the period 1960 to 1998.

Variation along the extensive margin does not, however, account for changes in task content within occupations such as is described in Levy and Murnane (1996), and is accordingly likely to provide an incomplete picture of changing job task requirements. Hence, we exploit changes between 1977 and 1991 in skill content measures within occupations - the 'intensive' margin - using matched occupations from the Revised Fourth Edition of the Dictionary of Occupational Titles. This approach also has limitations. In the Revised Fourth Edition of the DOT, only a subset of occupations was reevaluated by DOT examiners, and moreover the year of reevaluation varied among occupations. ${ }^{23}$ Measured changes along the intensive margin are therefore likely to provide a conservative picture of the total change in occupational task content.

Although the DOT provides unique, observational measures of occupational task requirements, it has a number of well-known limitations documented by Miller et al (1980). These include limited sampling of occupations (particularly in the service sector), imprecise definitions of measured constructs, and omission of important job skills. One result of these problems is that DOT measures of the skills required in particular occupations are likely to be imprecisely estimated, particularly for

\footnotetext{
${ }^{22}$ Because the CPS labor force sub-sample only includes those employed during the survey reference week, it is intrinsically weighted by weeks of labor force participation.

${ }^{23}$ The weighted fraction of employment reevaluated between 1978 and 1990 in our data is 73 percent, with 32 percent reevaluated between 1978 and 1984 and 41 percent reevaluated between 1985 and 1990. Occupations were chosen for reevaluation by DOT examiners partly on the expectation that their content had changed since the previous evaluation. Hence, the subset that was reevaluated may have changed more than the subset that was not.
} 
occupations outside of manufacturing. Despite these limitations, the DOT contains to our knowledge the best time series information available on the skill requirements for detailed occupations economywide. ${ }^{24}$ Researchers who have used the DOT for related analyses include Howell and Wolff (1991), Ingram and Neumann (2000), Spenner (1983 and 1990), and Wolff (1996). Our focus on routine versus non-routine tasks, choice of DOT variables, and analysis of change in job content within occupations across successive DOT editions is distinct from these studies. ${ }^{25}$

\section{a. Selecting DOT measures of routine and newoutine tasks}

To identify plausible indicators of the skills discussed above, we reduced the DOT measures to a relevant subset using their textual definitions and detailed examples provided by the Handbook for Analyzing Jobs (U.S. Department of Labor, 1972), the guidebook used by the DOT examiners. Based on these definitions and examination of means by major occupation for the year 1970, we selected five variables that appeared to best approximate our skill constructs. Definitions of these variables and example tasks from the Handbook for Analyzing Jobs are provided in Appendix Table $1 .{ }^{26}$

To measure non-routine cognitive tasks, we employ two variables, one to capture interactive and managerial skills and the other to capture analytic reasoning skills. The variable DCP codes the extent to which occupations involve Direction, Control, and Planning of activities. This variable takes on consistently high values in occupations involving substantial non-routine managerial and interpersonal tasks. The variable GED-MATH, our second measure of non-routine cognitive tasks, codes the quantitative skills ranging from arithmetic to advanced mathematics that are required in occupations. We employ this variable as a measure of occupations' analytic and technical reasoning requirements.

We identified STS, the acronym for adaptability to work requiring Set limits, Tolerances, or Standards, as an indicator of routine cognitive tasks and selected the variable FINGDEX (an

\footnotetext{
${ }^{24}$ The Department of Labor's successor to the DOT, the O*NET, offers potentially more up to date information on occupational characteristics. O*NET does not, however, provide time series data on job content within occupations. ${ }^{25}$ Spenner (1983) provides a careful analysis of changes in occupational content between the 3 rd and 4 th editions of the DOT.
} 
abbreviation of Finger Dexterity) as an indicator of routine manual activity. ${ }^{27}$ Finally, we selected EYEHAND, short for Eye-Hand-Foot coordination, as a measure of non-routine motor tasks. This variable takes on high values in occupations requiring physical agility, such as firemen.

While we believe the selected measures are the most appropriate available from the DOT, we are sensitive to the concern that our choice of variables could be viewed as arbitrary (or worse). Hence, we test whether the chosen variables are logical candidates and explore whether initial results are similar if we employ alternative, composite variables generated by principal components analysis.

\section{b. Are these the correct DOT measures? A predictive test}

Observe that our model makes three specific predictions about which industries should have adopted computer capital most vigorously as its price declined: 1) industries intensive in routine cognitive and routine manual tasks - for which computers directly substitute for human labor; 2) industries intensive in non-routine cognitive tasks - with which computers complement human labor; and 3) industries that employ minimal non-routine manual task input - since non-routine manual tasks are not very amenable to computerization. If it were possible to measure industry task input prior to the computer era, these task measures should substantially predict subsequent patterns of computer adoption.

To implement a variant of this test, we pair DOT occupational task measures with industry occupational distributions from the 1960 Census to fit the following model:

$$
\Delta C_{k, 1959-1997}=\alpha+\beta T_{k, 1959}+\varepsilon_{k},
$$

where $\Delta C_{k, 1959-1997}$ is the percentage point change between 1959 and 1997 in the share of industry $k$ employees using a computer on the job, $T_{k .1959}$ is a measure of industry task intensity in 1959 from the

\footnotetext{
${ }^{26}$ Supplemental tables providing a description of all DOT measures, the means of selected measures by major occupation, and a set of cross-industry correlations are available from the authors.

${ }^{27}$ As is clear from Appendix Table 1, there is overlap between our measures of routine manual and routine cognitive tasks. Although STS is weighted toward routine clerical and numerical tasks such as transcribing and calculating, and FINGDEX is weighted toward routine manual tasks such as feeding machines and performing repetitive movements,
} 
DOT, and $\varepsilon$ is an error term. ${ }^{28}$ Although we do not have a direct measure of the level of industry computer use in 1959 , computer penetration was close to zero in all industries at this time; hence, the 1997 industry level is effectively the change since 1959. To test whether the DOT task measures provide explanatory power beyond standard education variables, we also fit models that include a measure of industry college graduate employment in 1959.

Estimates of (9) are found in Panel A of Table 2. Most notable from the table is that four of five task measures have the predicted sign. Industries intensive in non-routine cognitive tasks and intensive in routine cognitive and routine motor tasks in 1959 computerized significantly more than other industries over the subsequent four decades. Conversely, industries intensive in non-routine manual tasks computerized substantially less than others. As is visible in row (2) of the table, all results are robust to inclusion of industry college graduate employment in 1959. The one unexpected pattern in the top panel of Table 2 is that the DOT measure of non-routine cognitive/interactive tasks does not predict subsequent computerization well. Overall, we take these patterns as preliminary evidence that our task measures primarily capture the task dimensions outlined by our model.

To explore whether similar patterns prevail when we characterize industry task content using reasonable alternatives to our five DOT variables, we performed principal components analyses (PCA) to pool variation from each selected DOT task measure with several other plausible alternatives. ${ }^{29} \mathrm{We}$ estimated equation (9) using these composites in place of the direct DOT measures. To facilitate comparisons between the analogous coefficients in the two panels of Table 2 , all DOT and composite variables are standardized to have mean zero and variance one.

The patterns displayed in Panel B of Table 2 are largely comparable to the patterns using the direct the correlation between the measures is high (0.6) using 1980 Census weights) and examples of both routine manual and cognitive tasks appear for each measure in the Handbook for Analyzing Jobs.

${ }^{28}$ Specifically, we apply 1977 DOT measures by occupation to the 1960 Census and aggregate to the industry level.

29 The PCA extracts eigenvectors that maximize common variation among selected measures, each standardized with mean zero and variance one, subject to the constraint that the sum of squared weights in the eigenvector equals one. 1t 
DOT measures. For three of the five task types, non-routine cognitive, routine manual, and non-routine manual, the coefficient on the relevant composite and the coefficient on the individual DOT variable both have the hypothesized sign and are significantly different from zero. For the non-routine cognitive/interactive task measure, the composite measure predicts somewhat better than the single DOT variable. For the routine cognitive task measure, the opposite is the case.

While it would be possible to perform our entire analysis using the composites in place of the direct DOT measures, we find this approach unappealing. The composites are particularly problematic when analyzing within-occupation changes in the DOT since they do not correspond to any specific occupational changes observed by DOT examiners. We therefore concentrate the analysis on the direct measures. However, we perform a second test of our variable choices below by re-estimating key results using the composite measures in place of the direct DOT variables.

\section{Computerization and trends in task input: 19591998}

\section{a. Economy-wide trends}

Figure 1 illustrates the extent to which changes in the occupational distribution over the period 1960 - 1998 resulted in changes in the task content of the work done by the U.S. labor force. ${ }^{30}$ The proportion of the labor force employed in occupations that made intensive use of non-routine cognitive tasks - both interactive and analytic - increased substantially. In contrast, the percentage of the labor force employed in occupations intensive in routine cognitive, routine manual and non-routine manual activities declined over the period.

As can be seen in detail in Table 3, while both measures of non-routine cognitive tasks trended upward during the 1960 s, the upward trend in each accelerated substantially thereafter, and was most

can be shown that if measurement error in the selected variables is iid, the PCA extracts maximal true variation. Details of our compositing exercise are provided in the Data Appendix.

${ }^{30}$ In this figure and the remainder of the analysis, each DOT measure is scaled from zero to ten with higher values indicating greater task input. Since these are not standardized metrics, it is potentially misleading to compare the magnitude of changes across dependent variables. In section 6 , we translate task demands into the more familiar metric of educational requirements. 
rapid during the 1980 s and 1990 s. Equally notably, routine cognitive and routine manual tasks were both increasing during the 1960 s, prior to commencing a decline in the 1970 s, which became more rapid in each subsequent decade. The steady trend against non-routine manual tasks, however, predates the computer era. These aggregate patterns are also apparent for each gender (Panel B of Table 3), although given the large increases in women's educational attainment and labor force participation in recent decades, the patterns are more pronounced for women. ${ }^{31}$

For reference, Appendix Table 2 tabulates the DOT task measures by major educational group. Notably, while three of five skill variables are monotonic in educational attainment, the two measures of routine tasks - cognitive and manual - show a U-shaped relationship to education; in particular, high school graduates perform substantially more of both types of routine task than either high school dropouts or college graduates. This non-monotonicity suggests that the DOT measures may provide information about job task requirements distinct from standard educational categories.

\section{b. Task upgrading: A withizindustry phenomenon?}

Changes in the task content of the work done by the U.S. labor force could stem from substitution of computer capital for routine labor inputs within detailed industries, as our model suggests. Alternatively, shifts in product demand favoring sectors intensive in non-routine activities could give rise to economy-wide increases in the utilization of non-routine tasks. Since the focus of our conceptual model and empirical analysis is on changes in task demands within industries, we explore the extent to which changes in measured job content stem from within-industry shifts.

A standard decomposition of the change in the use of task $j$ in aggregate employment between years $t$ and $\tau\left(\Delta T_{j \tau}=T_{j \tau}-T_{j t}\right)$ into a term reflecting the reallocation of employment across sectors and a term reflecting changes in task $j$ input within industries is given by

\footnotetext{
${ }^{31}$ Notably, in the 1960s, women were more (less) concentrated in routine manual and cognitive tasks (non-routine cognitive analytic and interactive tasks) than were men. By 1998, the gender distributions of tasks had substantially converged and women performed fewer routine cognitive tasks than did males.
} 


$$
\Delta T_{j \tau}=\sum_{k}\left(\Delta E_{k \tau} \gamma_{j k}\right)+\sum_{k}\left(\Delta \gamma_{j k \tau} E_{k}\right)=\Delta T_{j \tau}^{b}+\Delta T_{j \tau}^{w},
$$

where $k$ indexes industries, $E_{j k \tau}$ is the employment of workers in task $j$ in industry $k$ in year $\tau$ as a share of aggregate employment in year $\tau, E_{k \tau}$ is total employment (in FTES) in industry $k$ in year $\tau$, $\gamma_{j k \tau}$ is the mean of task $j$ in industry $k$ in year $\tau, \gamma_{j k}=\left(\gamma_{j k \tau}+\gamma_{j k}\right) / 2$, and $E_{k}=\left(E_{k \tau}+E_{k t}\right) / 2$. The first term $\left(\Delta T_{j r}^{b}\right)$ reflects the change in aggregate employment of task $j$ attributable to changes in employment shares between industries that utilize different intensities of task $j$. The second term $\left(\Delta T_{J_{r}}^{w}\right)$ reflects within-industry task change.

Table 4 presents between- and within-industry decompositions of our five DOT task measures during each decade from 1960 to 1998 . These decompositions show quite consistent patterns of task change. Both measures of non-routine cognitive task input - interactive and analytic - show strong within-industry growth after the 1970s. For the non-routine cognitive/interactive task measure, the growth in economy-wide input of this task over four decades is almost entirely a within-industry phenomenon; moreover, the rate of within-industry growth accelerates from decade to decade. For the non-routine cognitive/analytic task measure, the within-industry growth rate accelerates after the 1970s. Prior to this decade, the growth of non-routine cognitive/analytic task input is primarily a between-industry phenomenon.

Trends in routine task input, both cognitive and manual, also follow a striking pattern. During the 1960s, both forms of input increased due to a combination of between- and within-industry shifts. In the 1970s, however, within-industry input of both tasks declined, with the rate of decline accelerating.

As distinct from the other four task measures, we observe steady within- and between-industry shifts against non-routine manual tasks for the entire four decades of our sample. Since our conceptual framework indicates that non-routine manual tasks are largely orthogonal to computerization, we view this pattern as neither supportive nor at odds with our model. 
In net, these data indicate that within-industry shifts dominate for the most part the task trends that we seek to analyze, particularly from the 1970 s forward. We now turn to an analysis of the role that computerization has played in these within-industry task shifts.

\section{c. The time pattern of industry task shifts: Do they predate the computer era?}

We begin the analysis of the relationship between computerization and industry task input by estimating the bivariate regression

$$
\Delta T_{j k \tau}=\alpha+\beta \Delta C_{j}+\varepsilon_{j k \tau}
$$

where $\Delta T_{j k \tau}=T_{j k \tau}-T_{j k \tau}$ is the change in industry input of task $j$ between years $t$ and $\tau$ and $\Delta C_{k}$ is the change between 1984 and 1997 in the percentage of industry workers using a computer at their jobs as estimated from the October Current Population Survey supplements of these years.

In estimating (11), we choose the period 1960 to 1998 because it encompasses the recent computer era and, as importantly, the prior decade. Although the widespread diffusion of desktop computers during the 1980 s and 1990 s represents a highly visible technology 'shock' - with the share of workers using a computer on the job rising from 25 to 51 percent between 1984 and 1997 - it bears emphasis that the era of rapid computer investment began in the 1970s (Autor, Katz and Krueger, 1998; Bresnahan, 1999). Hence, to the degree that industry computer proxies 'predict' occupational task change during the 1960 s, this would suggest that observed trends in task content in computer intensive sectors pre-date the computer era and hence are unlikely to be caused by computerization. Conversely, if the relationship between industry computer intensity and task change is not detectable until the 1970s or later, this is more likely to be consistent with a causal relationship.

Table 5 presents estimates of (11) for each of the four decades from $1960-1998$. Each dependent variable measures ten times the annualized industry level change in the average value of one of the task indicators. Figure 2 summarizes the time pattern of regression coefficients.

Industries that computerized relatively rapidly during the $1980 \mathrm{~s}$ and $1990 \mathrm{~s}$ increased the share of 
jobs requiring non-routine cognitive/analytic task input during these decades more than did other industries. However, this was not the case for prior decades. As illustrated in Figure 2, during the 1960s and 1970s, the industries that became the rapidly computerizing industries did not differentially increase input of non-routine cognitive/analytic tasks.

The pattern is somewhat different for the change in cognitive/interactive tasks. Industries that subsequently computerized intensively were already raising their input of cognitive/interactive tasks relatively more rapidly than other industries in the 1960 s and 1970s. However, the magnitude and statistical significance of this relationship increased substantially in the 1980s and 1990s, consistent with the acceleration in within-industry trends in Table 4 . In fact, the estimated impact of computerization on both measures of non-routine cognitive tasks accounts for eighty to one hundred percent of the observed within-industry growth in input of these tasks over $1980-1998 .^{32}$

The relationships between computerization and routine cognitive and routine manual task input present a mirror image of these patterns. During the 1960s, industries that subsequently underwent rapid computerization did not significantly shift their routine cognitive or routine manual task input relative to other industries. Beginning in the 1970s, these same sectors undertook rapid reductions in routine cognitive and routine manual task input. As above, the impact of computerization accounts for all of the observed within-industry reduction in routine task input between 1970 and 1990.

Consistent with our framework, there is no significant evidence that rapidly computerizing industries decreased their use of non-routine manual tasks more rapidly than did other industries during this period. During the 1990s, however, rapidly computerizing industries decreased the non-routine manual task intensity of work less rapidly than did other industries. ${ }^{33}$

\footnotetext{
32 Specifically, the intercept of the bivariate regression of the change in industry non-routine cognitive/analytic task input on computerization during the 1980 s and $1990 \mathrm{~s}$ is close to zero although the mean of the dependent variable is large and positive. In this sense, compulerization accounts for the entirety of the observed phenomenon.

${ }^{33}$ This result should be interpreted carefully. It is unlikely that computerization directly increases demand for nonroutine manual tasks; rather, the share of human labor devoted to non-routine manual tasks is likely to rise
} 
To further probe the robustness of our variable choices from the DOT, we estimated comparable models using the composite task measures developed from the pure DOT variables (Appendix Table 3). The time pattern of results for the composite estimates is for the most part comparable to that found in Table 5. In all cases, the relationship between computerization and the composite task measure is not statistically significant during the 1960s and becomes statistically and economically significant in subsequent decades. The decade of the 1970s presents some inconsistencies, however, indicating that our composites do not perform as well as the pure DOT measures.

\section{d. Employing contemporaneous measures of computerization}

The estimates above are consistent with the hypothesis that computerization during the 1980s and 1990s induced or accelerated industry level task shifts that were not (as) evident in the pre-computer era of the $1960 \mathrm{~s}$. To provide a broader test of the hypothesis that computerization accounts for these task shifts, we employ a contemporaneous measure of per-worker industry computer investment from the National Income and Product Accounts ('NIPA', U.S. Department of Commerce, 1993 and 1999). To measure industry computerization, we calculate the log of real computer investment per full-time equivalent employee (FTE) over the course of the decade. ${ }^{34}$ Since we are interested in the impacts of computerization as distinct from overall industry capital deepening, we also construct a measure of the change in the log industry capital labor ratio.

We use these data to estimate stacked first-difference industry task shift models of the form

$$
\Delta T_{j k t}=\alpha+\delta_{70-80}+\delta_{80-90}+\delta_{90-98}+\beta_{1} C I_{k \tau}+\beta_{2} \Delta K_{k t}+\varepsilon_{j k \tau},
$$

where $C I$ is $\log$ industry investment in computer capital per FTE over the contemporaneous decade,

mechanically as routine tasks are displaced. For example, a constant number of workers doing non-routine manual work such as cleaning and serving would account for a growing share of employment in computer-intensive sectors. ${ }^{34}$ Note that we do not use the change in this measure since the level proxies the flow of new computer capital into an industry over the decade. The NIPA data are also employed by Berndt, Morrison and Rosenblum (1995) and Autor, Katz, and Krueger (1998). We matched data from the Census, CPS, and DOT to NIPA data in 42 aggregated industries covering all private industry sectors except private household services. Because the NIPA capital variables are measured at a higher level of aggregation than our dependent variables, we estimate Huber-White robust standard errors that account for clustering at the NIPA sectoral level. See the Data Appendix for details. 
$\Delta K$ is the change in the log industry capital labor ratio (also measured in FTEs), the $\delta^{\prime} s$ are time dummies equal to one in each of the post-1960s decades corresponding to their subscripts, and $\alpha$ is a common intercept. In this specification, the $\delta^{\prime} s$ measure the trend change in industry task input in the 1970 s, 1980s, and 1990s relative to the base period of the 1960s. Hence, the key empirical question is whether by conditioning on measures of industry computer investment, we can explain the trend changes in task input measured by the $\delta^{\prime} s$.

Note that in estimating this equation, it is not necessary to interpret the industry computer investment measure, $C I_{i k t}$, as 'exogenous' (which it surely is not). As underscored by our theoretical model, the exogenous variable in our analysis is the economy-wide decline in the price of computer capital. Accordingly, the variation we exploit in (12) stems from industries' equilibrium response to this price decline as they shift the quantities and sources of task input from human to computer capital according to the new price schedule. ${ }^{35}$

Table 6 displays estimates of (12). The NIPA measure of computer investment consistently predicts relative declines in industry employment of both routine cognitive and manual tasks and relative growth in employment of non-routine cognitive tasks, both analytic and interactive. By comparing the decadal intercepts $\left(\delta^{\prime} s\right)$ in the first column of each panel to the observed decadal changes found at the bottom of the table, one can calculate the fraction of the observed change in the task measure explained by industry computer investment. Using the $1960 \mathrm{~s}$ as the baseline, these comparisons indicate that computer investment can more than fully explain the trend increase in both measures of non-routine cognitive task input since the 1960s, and accounts for over eighty percent of the trend decline in routine cognitive and manual tasks. ${ }^{36}$ Hence, computerization has substantial power in explaining the observed trend shifts in industry task input in each of the three decades following the

\footnotetext{
${ }^{35}$ As demonstrated in Table 2, the ability of industries to respond to these price changes depends importantly upon the mix of task inputs that they employ.
} 
A notable pattern in these results is that the estimated impact of capital deepening on changes in industry skill demands is statistically significant in only one of five models, non-routine manual tasks. Yet, the coefficient on computer investment is significant in all five models that contain the measure of capital deepening. Consistent with findings of Autor, Katz, and Krueger (1998) and Bresnahan, Brynjolfsson and Hitt (forthcoming), these results indicate that there appears to be something distinctive about computer capital's relationship with industry task demands apart from the well-known pattern of capital-skill complementarity (Griliches, 1969).

\section{Computerization and contemporaneous task shifts at the industry, occupation and educational level, 19801998}

It is possible to argue that the preceding results primarily provide an explanation for the widely documented pattern that during recent decades computer intensive industries increased their college graduate employment and decreased their high school graduate employment more than did other industries. ${ }^{37}$ Our contention, however, is that changes in the demand for workplace tasks are an underlying cause - not merely a reflection - of relative demand shifts favoring educated labor. If so, educational upgrading should be only one among several margins through which industries alter task input. Underlying shifts in task demand should also yield pervasive changes in task content that are visible within (as well as across) education and occupation groups.

To explore this implication, we examine changes in the task content of work within education and occupation categories over the two most recent decades. As a baseline, we first analyze the contemporaneous correlations between computerization and within-industry changes in task content

\footnotetext{
${ }^{36}$ For example, the calculation for routine cognitive tasks is: $[((-0.019-0.089)+0.040+(-0.122-0.089)+0.002+$ $\left.((-0.216-0.089)+0.041)^{*} .8\right] /\left(\left[(-0.019-0.089)+(-0.122-0.089)+(-0.216-0.089)^{*} .8\right]=0.87\right.$. Note that changes over 1990-98 are down-weighted by 20 percent due to the shorter time interval.

${ }^{37}$ Cf., Autor, Katz and Krueger (1998), Berman, Bound and Griliches (1994), Berman, Bound and Machin (1998), and Machin and Van Reenen (1998). The logic would be that because workers at higher levels of education appear to hold comparative advantage in non-routine relative to routine tasks (Appendix Table 2), industries undergoing rapid
} 
between 1980 and 1998. Next, we examine whether within-industry task shifts are present even among workers with the same educational attainments. Finally, we exploit direct field observations from successive revisions of the DOT to ask whether computerization yielded commensurate shifts in task content within nominally identical occupations. In the concluding section of the paper, we collect these strands to quantify the contribution of computerization-induced changes in the task content of work to recent demand shifts favoring educated labor.

\section{a. Extensive changes within industries and within education groups: 1980998}

Panel A of Table 7 presents a series of estimates in which the dependent variable is the withinindustry change between 1980 and 1998 in each of the five DOT task measures. The explanatory variable is the change in industry computer use between 1984 and 1997, which in this case is a contemporaneous measure. These results underscore the story told by Tables 5 and 6 . Industries that rapidly computerized during the 1980s and 1990s undertook large relative increases in the share of jobs requiring high levels of non-routine cognitive/interactive and cognitive/analytic task input, and decreased the share requiring routine cognitive and manual tasks.

These changes in industry task content have two components. One is educational upgrading. As has been widely documented, computerizing industries have substituted towards college-educated workers who, by our analysis, appear to hold a comparative advantage in non-routine cognitive tasks (cf. Appendix Table 2). A second component of these task shifts (not previously explored), is task upgrading within education groups. Industries undertaking computerization may shift the job tasks of workers of comparable education towards non-routine and against routine tasks.

A unique virtue of our data is that it allows us to gauge the importance of both channels of task change and estimate the contribution of computerization of each. To perform this decomposition, we estimate a variant of equation (11) in which the dependent variable is the within-industry change in the 
mean of each DOT measure among workers who have the same educational attainments. ${ }^{38}$ Since we pair the 1977 DOT task content measures to education-group-specific industry observations for 1980 and 1998, observed changes in task input stem solely from shifts in occupational distributions within education groups within industries. To conserve space, we present and discuss results for high school graduates and summarize results for all education groups in Figure 3. ${ }^{39}$

The weighted means of the task measures for high school graduates (Panel B of Table 7) indicate that during 1980 to 1998 , the task structure of high school graduates employment shifted towards nonroutine cognitive/interactive tasks and away from routine cognitive and routine manual tasks. Estimates of (11) for high school graduates reveal that these task shifts were significantly more pronounced in industries undergoing rapid computerization. Comparison of the estimated intercepts for these models relative to their weighted means reveals that observed high school graduate employment shifts against occupations intensive in routine cognitive and manual tasks and towards occupations intensive in nonroutine cognitive tasks were essentially entirely driven by changing employment patterns within rapidly computerizing sectors.

As is visible from Figure 3, industry-level computerization is associated with within-industry shifts towards non-routine and against routine tasks within essentially all education groups. A decomposition analogous to that in equation (10) (shown in Table 8) reveals the importance of within-education group shifts to the overall pattern of task change. In all but the case of non-routine manual tasks, within education group task upgrading explains a substantial share - 45 to 91 percent - of observed withinindustry task upgrading over these two decades. Hence, the impact of computerization is not confined to widely observed educational upgrading; within-education group changes in task structure appear at

\footnotetext{
${ }^{38}$ In particular, we replace $\Delta T_{j k \tau}$ in (11) with $\Delta T_{j k l \tau}$ where $l$ denotes education groups within industries.

${ }^{39}$ Estimates comparable to Table 7 Panel B for other education groups are found in Appendix Table 4 . The pattern of results for workers with some college is virtually identical to that of high school graduates. The relationships are almost all of the expected sign for college graduates and high school dropouts but are primarily not statistically significant. A likely explanation for the weak college graduate results is 'topping out.' Because in 1980, college
} 
least equally important.

Notably, in a recent analysis of the inter-industry wage structure, Bartel and Sicherman (1999)

found that technology-intensive industries select workers of greater unobservable skill conditional on education. Our results suggest a likely causal channel for this finding: within nominally similar education categories, these industries have differentially shifted the task content of employment against routine, repetitive tasks and towards tasks demanding cognitive flexibility.

\section{b. Computerization and changes in occupational task content: 197P991}

The task shifts documented above are measured exclusively by shifts in occupational composition (the extensive margin). Our framework further implies that pervasive shifts in task demands should induce parallel changes along the intensive margin. In this section, we exploit direct job evaluations from successive editions of the DOT to explore whether computerization has yielded commensurate changes in task content within nominally identical occupations. Specifically, we estimate the equation

$$
\Delta T_{m k \tau}=\alpha+\beta \Delta C_{m}+\varepsilon_{m k \tau},
$$

where $\Delta T_{m k \tau}$ is the change in observed occupational task content between the 1977 and 1991 in 3-digit COC occupation $m$, and $\Delta C_{m}$ is the change in occupational computer penetration measured by the CPS. $^{40}$

To make this test as clean as possible, our DOT 1977 - 1991 comparison data set is constructed using only the subset of occupations appearing in the 1977 DOT and represented by the 1973 CPS file (National Academy of Sciences, 1981) that provides our DOT-COC crosswalk. In addition, although the distribution of employment in DOT occupations (of which there are approximately 12,000) has doubtless shifted within COC occupations in recent decades, we hold this distribution fixed at the 1973 level to again exclude extraneous variation. Accordingly, the variation exploited in estimates of cognitive and routine manual tasks, this left little room for the task measures to attain further extremes.

${ }^{40}$ The Fourth and Fourth Revised editions of the DOT were published in 1977 and 1991 respectively. For consistency with the analysis above, we use the CPS compulerization and education measures for 1984 to 1997. 
equation (13) stems entirely from DOT examiners' reevaluations of the task content of individual occupations between 1977 and 1991.

For each task measure, we present the results from two specifications in Table 9. The first includes only the occupational computerization measure. To explore whether intra-occupational task change is implicitly captured by shifts in the educational distribution of employees in an occupation, the second specification adds the contemporaneous change in the percentage of workers in the occupation who are college graduates.

The most visible change in occupational task content between 1977 and 1991 was a pronounced decrease in routine cognitive tasks. A regression of the routine cognitive task measure on occupational computerization reveals that input of this task declined by substantially more in rapidly computerizing occupations. Comparison of the intercept of this regression to the weighted mean of the dependent variable indicates that the implied impact of computerization is more than sufficient to explain the observed mean shift against routine cognitive tasks over 1977 to 1991 . A second notable pattern is the positive relationship between occupational computerization and the input of non-routine cognitive/analytic tasks. Even though the average level of non-routine cognitive/analytic tasks declined slightly within occupations, the level increased significantly in rapidly computerizing occupations. Finally, the input of cognitive/interactive tasks increased within occupations (Column 2), and this shift was significantly greater in more rapidly computerizing industries.

We find little relationship between computerization and changes in the routine manual task content of occupations, however. Interestingly, computerization predicts significant increases in the nonroutine manual task content of occupations, a pattern also noted at the industry level.

Comparison across the two specifications in each panel demonstrates that the relationship between computerization and within-occupation task change is quite insensitive to inclusion of the college graduate employment share measure. Apparently, observed educational upgrading within occupations does not provide an adequate summary measure of shifts in occupational task content. 


\section{Computers, task structure, and the demand for college educated labor}

Are the pervasive task shifts documented above economically significant? To answer this question, we draw together the estimated impacts of computerization on task change within industries, within education groups and within occupations to calculate their net contribution to the demand for skill as conventionally measured by educational attainment.

Since units of task input do not have a natural scale, we translate task inputs into educational requirements using a "fixed coefficients" model of occupational education requirements in 1970 as a function of occupational task inputs measured by the 1970 DOT. Specifically, we estimate:

$$
N_{c}^{m}=\alpha+T_{m} \lambda+\varepsilon_{m}
$$

where $N_{c}^{m}$ is the employment share (in FTEs) of college graduates in occupation $m, T_{m}$ is a column vector containing the DOT means of our routine and non-routine skill measures, and $\lambda$ is a conformable row vector of coefficients. $\hat{\lambda}$ is therefore an estimate of college versus non-college demand as a function of occupational tasks.

We then translate our estimates of changes in job tasks induced by computerization (Tables 6 and 7) into estimates of implied changes in college versus non-college employment along the extensive margin by calculating

$$
\hat{\Delta} N_{c \tau}=\sum_{k} \gamma_{k \tau} \hat{\Delta} T_{k \tau} \hat{\lambda}
$$

where $\hat{\Delta} T_{k \tau}$ is a vector of predicted change in industry $k^{\prime} s$ input of each of our five task measures due to computerization between times $t$ and $\tau$ from estimates of equation (11) and (12), $\gamma_{k \tau}$ is industry $k^{\prime} s$ average share of employment between $t$ and $\tau . \hat{\Delta} N_{c t}$ is therefore the implied impact of computerinduced task shifts on the college graduate share of total employment. Similarly, we incorporate predicted changes on the intensive margin of task input over 1980 to 1998 by adding to $\hat{\Delta} T_{k \tau}$ the vector $\hat{\Delta} T_{m \tau}$, which is the change from equation (13) in within occupation tasks attributable to 
computerization (Table 9). ${ }^{41}$ Hence, this exercise asks by how much the college employment share would have needed to increase between 1970 and 1998 to satisfy contemporaneous computer-induced task shifts, assuming that college graduates continued to perform the same tasks (on average) as they did in $1970 .^{42}$

Two caveats apply to these estimates. First, given the limitations of the DOT discussed earlier, estimates of $\lambda$ are likely to be biased towards zero by measurement error. This will reduce our estimates of $\Delta N_{c \tau}$. Second, because equation (15) is a fixed coefficients model of education demand as a function of job tasks, it neglects task prices. To the degree that the implicit prices of non-routine tasks have risen (fallen) since 1970, our calculations will under- (over-) state accompanying demand shifts favoring non-routine tasks, and vice versa for measured demand shifts against routine tasks. Detailed calculations of (15) are found in Table 10. Panels A tabulates estimates of $\hat{\Delta} T_{k \tau}$ for $1970-1998$ and 1980 - 1998 excluding and including task changes on the intensive margin. Panel B translates these task shifts into units of college graduate employment in percentage points.

As is visible in Panel A, task changes on the extensive margin attributable to computerization explain 1.8 percentage points of the growth in college vs. non-college employment over $1980-1998$

${ }^{41}$ In addition, there is a third (interaction) term in the sum of computer contributions to task upgrading. The total contribution of computerization to task change can be written as:

$$
\Delta T_{\tau}=\sum_{m} \hat{\gamma}_{\tau}^{m} \cdot \hat{T}_{\tau}^{m}-\sum_{m} \gamma_{t}^{m} \cdot T_{t}^{m}=\sum_{m}\left(\hat{\gamma}_{\tau}^{m}-\gamma_{\tau}^{m}\right) \cdot T_{t}^{m}+\Sigma\left(\hat{T}_{\tau}^{m}-T_{t}^{m}\right) \cdot \gamma_{t}^{m}+\sum_{m}\left(\hat{\gamma}_{\tau}^{m}-\gamma_{\tau}^{m}\right)\left(\hat{T}_{\tau}^{m}-T_{t}^{m}\right)
$$

where $m$ subscripts occupations, $\gamma$ 's denote occupational shares of employment, and the 'hat' overscore $(\hat{\gamma})$ indicates an estimated occupational shift attributable to computerization. The first term on the right hand side of the above equation measures the task change due to within-industry occupational shifts attributable to computerization, holding constant the task content of occupations at the initial level in $t$ (this term is given by Table 7). The second term measures the change due to within-occupation task shifts, holding constant the distribution of occupational employment at the initial level (this term is given by Table 9). The third term measures the interaction of withinindustry and within-occupation task shifts between time $t$ and $\tau$. Because computerizing industries experienced disproportionate growth in occupations that rapidly computerized, there is a positive covariance between ivithinindustry and within-occupation components. We calculate this third term and add it to (15).

${ }_{42}$ Although as demonstrated above, task upgrading takes place along many margins - including within education groups - our objective here is to quantify the total impact of these shifts by translating them into one hypothetical margin: the demand for college educated labor. We estimate (14) using data from the 1970 Census on the task structure of employment by education group. 
and explain 2.0 percentage points of this growth over $1970-1998$. Slightly more than half of this contribution is accounted for by shifts favoring non-routine cognitive tasks, with the remainder explained by shifts against routine cognitive and manual tasks. ${ }^{43}$

Adding the effect of changes along the intensive margin, $\hat{\Delta} T_{m \tau}$, more than doubles the magnitude of this impact. Computerization is estimated to have increased the college graduate employment share by 5.0 percentage points over $1980-1998$ and 5.3 percentage points over $1970-1998$. Moreover, because the intensive margin change is only measured during 1977 to 1991 , it is likely that a longer time series would show that these shifts have even greater explanatory power.

For reference, the estimate of 5.0 percentage points can be compared to the actual change in college graduate employment between 1980 and 1998, which is 6.83 percentage points. However, this is not the most appropriate comparison since increases in college employment are likely to be driven in part by secular trends in the supply of college graduates as well as shifts in demand per se. To make a more formal comparison, we employ a simple constant elasticity of substitution framework to translate induced employment shifts into log relative demand shifts for college equivalent labor. In this framework, we assume that aggregate output, $Q_{t}$, is produced using two factors, college $(c)$ and high school $(h)$ equivalents in the production function

$$
Q_{r}=\left[\alpha_{r}\left(a_{r} N_{c t}\right)^{\rho}+\left(1-\alpha_{t}\right)\left(b_{t} N_{h t}\right)^{\rho}\right]^{\frac{1}{\rho}},
$$

where $N_{c l}$ and $N_{h t}$ are the quantities of employed college equivalents and high school equivalents in period $t, a_{t}$ and $b_{t}$ represent skilled and unskilled labor-augmenting technological change, $\alpha_{t}$ is a time-varying technology parameter that can be interpreted as indexing the share of work activities allocated to skilled labor, and $\rho$ is time invariant. The aggregate elasticity of substitution between

\footnotetext{
${ }^{43}$ The increased demand for non-routine manual tasks makes a small offsetting contribution.
} 
college and high school equivalents is given by $\sigma=1 /(1-\rho){ }^{44}$

Under the assumption that the economy operates on its labor demand curve so that college and high school equivalents are paid their marginal products, we can use (16) to solve for the ratio of marginal products of the two labor types, yielding the relationship between relative wages $\left(w_{c t} / w_{h t}\right)$ and relative supplies $\left(w_{c t} / w_{h t}\right)$.

$$
\ln \left(w_{c t} / w_{h t}\right)=1 / \sigma\left[D_{t}-\ln \left(N_{c t} / N_{h t}\right)\right]
$$

Rearranging (17) and taking first differences, the change in the relative demand for college equivalent labor between times $t$ and $\tau$ in $\log$ quantity units can be written as ${ }^{45}$

$$
\Delta D_{\tau}=D_{\tau}-D_{t}=\Delta \ln \left[\left(w_{c \tau} N_{c \tau} / w_{h \tau} N_{h \tau}\right)\right]+(\sigma-1) \ln \left(w_{c \tau} / w_{h \tau}\right)
$$

Change in the relative demand for college equivalents can be written as the sum of the change in the $\log$ relative wage bill and a term that depends positively (negatively) on the change in the log college wage premium when $\sigma>1(\sigma<1)$.

In implementing this framework, we follow Autor, Katz and Krueger (1998) in employing an elasticity of substitution between college and non-college labor of $\sigma=1.4$, a figure that receives broad empirical support from the literature. ${ }^{46}$ Using our Census and CPS samples, we calculate that the estimated $\log$ relative demand for college graduate employment grew by approximately $10 \log$ points annually over $1970-1998$ and $7 \log$ points over $1980-1998$ (Panel C of Table 10).

Using these demand shift estimates as a benchmark, we can calculate the share of the estimated demand shift attributable to computer-induced task shifts. To make this comparison within our "fixed coefficients" framework, we estimate a version of (18) in which we allow $\rho \rightarrow-\infty$, which implies that

\footnotetext{
${ }^{44}$ Autor, Katz and Krueger (1998), Johnson (1997), and Katz and Murphy (1992) implement a similar model. Our implementation is closest to Autor, Katz and Krueger's, and we update their Table 2 to 1998 to perform the benchmark demand shift estimates against which we compare our fixed coefficient calculations. Because (16) exhibits constant retums to scale, we conserve notation by using $N_{c t}$ and $N_{h t}$ to refer to employment quantities and employment shares interchangeably.

${ }^{45} D_{t}=\sigma \ln \left(\alpha_{t} /\left[1-\alpha_{t}\right]+(\sigma-1) \ln \left(a_{t} / b_{t}\right)\right.$.
} 
$\sigma \rightarrow 0$, the relative demand for college equivalents is Leontif (i.e., fixed coefficients). In this special case, (18) reduces to

$$
\Delta D_{\tau}=\Delta \ln \left(N_{c \tau} / N_{h \tau}\right)=\ln \left(1+\left[\Delta N_{c \tau} / N_{c \tau}\right]-\ln \left(1+\left[\Delta N_{h \tau} / N_{h \tau}\right] .\right.\right.
$$

Here, changes in log relative demand are written entirely in terms of shifts in relative employment. ${ }^{47}$

To gauge the contribution of computerization to demand shifts, we replace $\Delta N_{c \tau}$ in (19) with $\hat{\Delta} N_{c \tau}$ the estimated computer-induced change in college graduate employment from equation (15).

For the period 1980 - 1998, task shifts induced by computerization are estimated to have increased $\log$ relative college demand by $2.8 \log$ points annually (Table 10, Panel C). Comparing this number to the estimated economy-wide shift of 6.7 log points over this period, we find that changes in task content explain approximately 40 percent of the observed shift. Notably, more than half of this impact is accounted for by (normally unobservable) shifts along the intensive margin. The analogous calculation for the three-decade interval finds that computer-induced task shifts explain approximately 30 percent of the demand shift favoring college graduates over $1970-1998 .^{48}$

In interpreting these estimates, we note that relative demand for college-educated labor in the U.S. increased substantially from the 1940s through the 1960s, decades prior to computerization (cf., Acemoglu, forthcoming; Autor, Katz and Krueger, 1998; Johnson, 1997; and Mishel, Bernstein and Schmitt, 1997). Hence, a claim that computerization has increased the relative demand for educated labor requires evidence that computerization has accelerated demand growth beyond trends prevailing during the 1960 s and earlier. It is therefore noteworthy that the estimates in Table 10 indicate that computerization contributed to more rapid growth in college employment in the 1970s relative to the

\footnotetext{
${ }^{46}$ Cf., Hamermesh (1993), Heckman, Lochner and Taber (1998), and Katz and Murphy (1992).

${ }^{47}$ Note that $\hat{\Delta} N_{h \tau}=-\hat{\Delta} N_{c \tau}$. For consistency with the fixed coefficients model, we use $\sigma=0$ for this calculation. If we used $\sigma=1.4$ instead, our estimate of the contribution of task shifts to observed college demand shifts would be significantly larger, as follows from the substantial increase in relative wages of college graduates over $1980-1998$. ${ }^{48}$ As with the N1PA estimates in Table 6, we perform all calculations for $1970-1998$ relative to the 1960 s. Specifically, we subtract off the 1960s trend task change from the task estimates for the 1970s, 1980s, and 1990s on the assumption that these trends predated computerization and should not be counted as potential computer impacts.
} 
1960 s, and that this impact was greater still during the 1980 s and 1990s. Hence, our evidence suggests that recent technological change has had an accelerating impact on the task structure of employment since the 1970s. Cumulatively, this impact appears to have contributed substantially to demand shifts favoring college-educated labor.

\section{Conclusion}

A number of influential studies report a positive correlation between technology investments and educational upgrading. Our study complements and advances this line of research. By conceptualizing job skill demands in terms of job tasks rather than the educational credentials of workers performing those tasks, our framework provides an account of how computerization and associated organizational changes alters the composition of job tasks. This framework rationalizes the observed correlation between computerization and increased use of educated labor and predicts pervasive shifts in workplace task structure that are not observable in conventional data sources. By exploiting consistent, representative, time series observations on the task structure of jobs from the Dictionary of Occupational Titles, we both affirm these predictions and find that they contributed substantially to demand shifts favoring educated labor over the past three decades. While the limitations of the DOT also place some constraints on the precision of our analysis, we believe it advances understanding of the evolving skill content of work. 


\section{References}

Acemoglu, Daron. 1998. "Why Do New Technologies Complement Skills? Directed Technical Change and Wage Inequality." Quarterly Journal of Economics. 113 (4), November, 1055 - 89.

Acemoglu, Daron. 1999. "Changes in Unemployment and Wage Inequality: An Alternative Theory and Some Evidence." American Economic Review, 89(5), December, 1259 - 78.

Acemoglu, Daron. forthcoming. "Technical Change, Inequality, and the Labor Market." Journal of Economic Literature.

Adler, Paul S. 1986. "New Technologies, New Skills." California Management Review, 29(1), 9 - 28.

Autor, David H., Lawrence F. Katz, and Alan B. Krueger. 1998. "Computing Inequality: Have Computers Changed the Labor Market?" Quarterly Joumal of Economics, 113(4), November, $1169-1214$.

Autor, David H., Frank Levy and Richard J. Murnane. 2001. "Upstairs, Downstairs: Computers and Skills on Two Floors of a Large Bank." mimeo, MIT, March.

Babbage, Henry P. 1883. "The Analytical Engine." Proceedings of the British Association.

Bartel, Anne P. Ichniowski, Casey and Kathryn Shaw. 2000. "New Technology, Human Resource Practices and Skill Requirements: Evidence from Plant Visits in Three Industries." mimeo, Carnegie Mellon University.

Bartel, Ann P. and Frank R. Lichtenberg. 1987. "The Comparative Advantage of Educated Workers in Implementing New Technology." Review of Economics and Statistics, 69(1), 1-11.

Bartel, Ann P. and Nachum Sicherman. 1999. "Technological Change and Wages: An Interindustry Analysis." Journal of Political Economy, 107(2), April, 285 - 325.

Berman, Eli, John Bound, and Zvi Griliches. 1994. "Changes in the Demand for Skilled Labor within U.S. Manufacturing Industries: Evidence from the Annual Survey of Manufactures." Quarterly Journal of Economics, 109, 367 - 397.

Berman, Eli, John Bound, and Stephen Machin. 1998. "Implications of Skill-Biased Technological Change: International Evidence." Quarterly Journal of Economics, 113, 1245 - 1279.

Berman, Eli and Stephen. 2000. "Skill-Biased Technology Transfer: Evidence of Factor Biased Technological Change in Developing countries." mimeograph, Boston University, January.

Berndt, Emst R. and Catherine J. Morrison. (1995) "High-Tech Capital Formation and Economic Performance in U.S. Manufacturing Industries: An Exploratory Analysis." Journal of Econometrics, 65, 9 - 43 .

Borghans, Lex and Bas Ter Weel. 2000. "What Happens When Agent T Gets a Computer?" mimeo, Maastricht University, October. 
Bound, John, and George Johnson. 1992. "Changes in the Structure of Wages in the 1980s: An Evaluation of Alternative Explanations," American Economic Review, 82, 371-392.

Bresnahan, Timothy F. 1999. "Computerization and Wage Dispersion: An Analytical Reinterpretation" Economic Journal, 109, June, $390-415$.

Bresnahan, Timothy F., Erik Brynjolfsson, and Lorin M. Hitt. Forthcoming. "Information Technology, Workplace Organization and the Demand for Skilled Labor: Firm-Level Evidence." Quarterly Journal of Economics.

Bryjolfsson, Erik and Lorin M. Hitt. 2000. "Beyond Computation: Information Technology, Organizational Transformation and Business Performance.” Journal of Economic Perspectives, Fall, $23-48$.

Caroli, Eve, and John Van Reenen. forthcoming. "Skill-Biased Organizational Change? Evidence from a Panel of British and French Establishments." Quarterly Journal of Economics.

Caselli, Francesco. 1999. "Technological Revolutions." American Economic Review, 89, 78 - 102.

Davis, Randy. 1984. "Diagnostic Reasoning Based on Structure and Behavior." Artificial Intelligence, 24, December, 347-410.

Doms, Mark, Timothy Dunne, and Kenneth R. Troske. 1997. "Workers, Wages, and Technology." Quarterly Journal of Economics, 112, 253 - 90.

Fernandez, Roberto. 1999. "Skill-Biased Technological Change and Wage Inequality: Evidence from a Plant Retooling." mimeo, Stanford University Graduate School of Business, June.

Garicano, Luis. 2000. "Hierarchies and the Organization of Knowledge in Production." Journal of Political Economy, 108(5), $874-904$.

Gera, Surendra, Wulong Gu and Zhengxi Lin. 2001. "Technology and the Demand for Skills in Canada: An Industry-Level Analysis" Canadian Journal of Economics, February.

Goldin, Claudia; Katz, Lawrence F. 1998. "The Origins of Technology-Skill Complementarity." Quarterly Journal of Economics. 113(3), August, 693 - 732.

Griliches, Zvi. “Capital-Skill Complementarity.” 1969. Review of Economics \& Statistics, 51(4), November, $465-68$.

Grimm, Bruce T. 1998. "Price Indexes for Selected Semiconductors, 1974 - 1996." Survey of Current Business, February.

Hamermesh, Daniel S. 1993. Labor Demand. New Jersey: Princeton University Press.

Heckman, James J., Lance Lochner, and Christoper Taber. 1998. "Explaining Rising Wage Inequality: Explorations with a Dynamic General Equilibrium Model of Labor Eamings with Heterogeneous Agents." Review of Economic Dynamics, 1(1), January, 1 - 58. 
Howell David R. and Edward N. Wolff. 1991. "Trends in the Growth and Distribution of Skills in the U.S. Workplace, 1960-1985." Industrial and Labor Relations Review, 44(3), April, 486 - 502.

Hounshell, David A. 1984. From the American System to Mass Production, 1800-1932: The Development of Manufacturing Technology in the United States. Baltimore: Johns Hopkins University Press.

Ingram, Beth F. and George R. Neumann. 2000. "The Returns to Skill." mimeo, University of Iowa, May.

Jaeger, David A. 1997. "Reconciling the Old and New Census Bureau Education Questions:

Recommendations for Researchers." Joumal of Business and Economics Statistics, 15, 300 - 309.

Johnson, George 1997. "Changes in Earnings Inequality: The Role of Demand Shifts." Journal of Economic Perspectives, 11, 41 - 54.

Jorgenson, Dale W. and Kevin J. Stiroh. 1995. "Computers and Growth." Economics of Innovation and New Technology, 3(3-4), $295-316$.

Jorgenson, Dale W. and Kevin J. Stiroh. 1999. "Information Technology and Growth." American Economic Review, 89(2), 109 - 115.

Juhn, Chinhui. 1999. "Wage Inequality and Demand for Skill: Evidence from Five Decades." Industrial and Labor Relations Review, 52(3), April, 424 - 43.

Juhn, Chinhui; Murphy, Kevin M; Pierce, Brooks. 1993. "Wage Inequality and the Rise in Returns to Skill." Journal of Political Economy, 101 (3), June, $410-442$.

Katz, Lawrence F. and David H. Autor. 1999. "Changes in the Wage Structure and Earnings Inequality." in Handbook of Labor Economics, vol. 3, O. Ashenfelter and D. Card, eds. (Amsterdam: North Holland).

Katz, Lawrence F. and Kevin M. Murphy. 1992. "Changes in Relative Wages, 1963-1987: Supply and Demand Factors." Quarterly Journal of Economics, 107, 35 - 78.

Levy, Frank, Anne Beamish, and Richard J. Murnane. 1999. "Computerization and Skills: Examples from a Car Dealership." mimeo, MIT Department of Urban Studies and Planning, November.

Levy, Frank and Murnane, Richard J. 1992. "U.S. Earnings Levels and Earnings Inequality: A Review of Recent Trends and Proposed Explanations." Journal of Econonic Literature, 30(3), September, $1333-1381$.

Levy, Frank and Richard J. Murnane. 1996. "With What Skills are Computers a Complement?" Anerican Economic Review. 86 (2) May, 258 - 262.

Lindbeck, Assar, and Dennis J. Snower. 2000. "Multitask Learning and the Reorganization of Work: From Tayloristic to Holistic Organization." Journal of Labor Economics 18, 353 - 76.

Machin, Stephen; Van Reenen, John. 1998. "Technology and Changes in Skill Structure: Evidence from Seven OECD Countries.” Quarterly Journal of Economics, 113 (4), November, 1215 - 44. 
Miller, Anne R., Donald J. Treiman, Pamela S. Cain and Patricia A. Roose (editors). 1980. Work, Jobs and Occupations: A Critical Review of the Dictionary of Occupational Titles. Washington, DC: National Academy Press.

Mishel, Lawrence, Jared Bernstein, and John Schmitt. 1997. "Did Technology Have Any Effect on the Growth of Wage Inequality in the 1980s and 1990s?" mimeo, Economic Policy Institute.

Mobius, Markus. 2000. "The Evolution of Work.” Mimeograph, Harvard University, September.

Mokyr, Joel. 1990. The Lever of Riches: Technological Creativity and Economic Progress. New York: Oxford University Press.

Murnane, Richard J. and Frank Levy. 1996. Teaching the New Basic Skills. New York: Free Press.

Murphy, Kevin M and Finis Welch. 1992. "The Structure of Wages." Quarterly Journal of Economics, 107(1), February, $285-326$.

Murphy, Kevin M and Finis Welch. 1993. "Occupational Change and the Demand for Skill, $1940-$ 1990." American Economic Review, 83(2), May, 122 - 36.

National Academy of Science, Committee on Occupational Classification and Analysis. 1981. "Fourth Edition Dictionary of DOT Scores for 1970 Census Categories." ICPSR Document \#7845, Ann Arbor Michigan.

Nelson, Richard R., and Edmund S. Phelps. 1966. "Investment in Humans, Technological Diffusion, and Economic Growth.” American Economic Review, 56.

Orr, Julian E. 1996. Talking about Machines: An Ethnography of a Modem Job. Ithaca: Cornell University Press.

Park, Jin Heum. 1994. "Estimation of Sheepskin Effects and Returns to Schooling Using the Old and the New CPS Measures of Educational Attainment," Princeton University, Industrial Relations Section Working Paper No. 338, December.

Pinker, Steven. 1997. How the Mind Works. New York: Norton.

Polanyi, Michael. 1966. The Tacit Dimension. New York: Doubleday.

Priebe, J.A., J. Heinkel, and S. Greene. 1972. "1970 Occupation and Industry Classifications in Terms of their 1960 Occupation and Industry Elements." Census Bureau Technical Paper \# 26.

Roy, A. D. 1951. "Some Thoughts on the Distribution of Earnings." Oxford Economic Papers.

Ruggles Steven, Matthew Sobek et. al.. 1997. Integrated Public Use Microdata Series: Version 2.0, Minneapolis: Historical Census Projects, University of Minnesota

Schultz, Theodore W. 1975. "The Value of the Ability to Deal with Disequilibria." Journal of Economic Literature, 13, 827 - 846. 
Simon, Herbert A. 1960. "The Corporation: Will it be Managed by Machines?" in M. L. Anshen and G. L. Bach (eds). Management and the Corporations, 1985, New York: McGraw-Hill, 17 - 55.

Spenner, Kenneth I. 1983. "Deciphering Prometheus: Temporal Change in the Skill Level of Work." American Sociological Review, 48, 824 - 837.

Spenner, Kenneth 1. 1990. "Skill: Meaning, Methods and Measures." Work and Occupations, 17(4), $399-421$.

Thesmar, David, and Mathias Thoenig. 2000. "Creative Destruction and Firm Organization Choice: A New Look into the Growth-Inequality Relationship." Quarterly Journal of Economics, 115(4), 1201 - 1238, November.

U. S. Department of Commerce. 1993. Fixed Reproducible Tangible Wealth of the United States, 1925-89. Washington, DC: U. S. Department of Commerce, Economics and Statistics Administration, Bureau of Economic Analysis.

U.S. Department of Commerce. 1999. Fixed Reproducible Tangible Wealth of the United States, 19251997. NCN-0229. Washington, DC: U.S. Department of Commerce, Economics and Statistics Administration, Bureau of Economic Analysis.

U.S. Department of Labor, Manpower Administration. 1972. Handbook for Analyzing Jobs, Washington, DC.

U.S. Department of Labor. 1939. Dictionary of Occupational Titles: First Edition. Washington, DC.

U.S. Department of Labor, Employment and Training Administration. 1977. Dictionary of Occupational Titles: Fourth Edition. Washington, DC.

U.S. Department of Labor, Employment and Training Administration. 1991. Dictionary of Occupational Titles: Revised Fourth Edition. Washington, DC.

Weizenbaum, Joseph. 1976. Computer Power and Human Reason. San Francisco: W.H. Freeman.

Welch, Finis.1970. "Education in Production." Journal of Political Economy. 78, 35 - 59.

Welch, Finis.2000. "Growth in Women's Relative Wages and Inequality Among Men: One Phenomenon or Two?" American Economic Review, May, 444 - 450.

Winston, Patrick H. 1999. "Why I am Optimistic." available at http://www.ai.mit.edu/people/phw/optimism.html, July, accessed 6/18/2000.

Wolff, Edward N. 1996. "The Growth of Information Workers in the U.S. Economy, 1950-1990: The Role of Technological Change, Computerization, and Structural Change." C.V. Starr Center for Applied Economics, New York University RR\#96-41.

Zuboff, Shoshana. 1988. In the Age of the Smart Machine. New York: Basic Books. 


\section{Data Appendix}

\section{A.1. Samples used from Current Population Survey and Census of Populations}

To calculate occupational and educational distributions economy-wide and within industries for 1960 to 1998, we used observations on all non-institutionalized, employed workers ages $18-64$ from the Census PUMS one percent samples for 1960, 1970, 1980, and 1990 (Ruggles and Sobek, 1997) and the Merged Outgoing Rotation Groups of the Current Population Survey for the years 1980, 1990, and 1998. All individual and industry le vel analyses are performed using as weights full-time equivalent hours of labor supply, which is the product of the individual Census or CPS sampling weight times hours of work in the sample reference week divided by 35 and, for Census samples, weeks of work in the previous year. Our method provides equal weight to each hour of labor input in the economy rather than over-weighting part-time hours as is implicitly done when using raw Census sampling weights. Because hours were not reported for the self-employed in the CPS prior to 1994, we assigned selfemployed workers in all CPS samples the average labor hours in their industry-education-year cell. In cases where industry hours supplied by education category were unavailable (due to an empty industryeducation-year cell), we assigned weekly hours as the mean of workers' education-year cells.

To attain comparable educational categories (high school dropout, high school graduate, some college, college-plus graduate) across the redefinition of Census's Bureau's education variable introduced in 1990 in the Census and in 1992 in the CPS, we use the method proposed by Jaeger (1997). In data coded with the pre-1992 education question (Census PUMS 1960, 1970, and 1980, and CPS MORG files 1980 and 1990), we defined high school dropouts as those with fewer than 12 years of completed schooling; high school graduates as those having 12 years of completed schooling; some college attendees as those with any schooling beyond 12 years (completed or not) and less than 16 completed years; and college plus graduates as those with 16 or more years of completed schooling. In data coded with the revised education question (1990 Census PUMS and 1998 CPS MORG file), we define high school dropouts as those with fewer than 12 years of completed schooling; high school graduates as those with either 12 completed years of schooling and/or a high school diploma or G.E.D.; some college as those attending some college or holding an Associate's Degree (either occupational/vocational or academic); and college plus as those with a B.A. or higher.

\section{A.2. Computing DOT Task Means for Census Occupation Categories (COCs)}

To compute DOT Task Means for 1970 CIC Occupations, we used a special version of the April 1971 CPS Monthly File issued by the National Academy of Sciences (1981) in which a committee of experts assigned individual DOT occupation codes and associated DOT measures to each of 60,441 workers in the sample. Because Census occupation categories are significantly coarser than DOT occupation categories, the 4111970 census occupation codes represented in the 1971 CPS were assigned a total of 3,886 unique 1977 DOT occupations. 'To convert this micro data sample into DOT task measures by CIC occupation, we used the CPS sampling weights to calculate weighted means of each DOT measure by occupation. Because the distribution of DOT occupations differs substantially by gender within COC occupation cells, we calculated DOT-occupation means for each occupation separately by gender. In cases where a COC cell contained exclusively males or females, we assigned the cell mean to both genders. This provided a set of 822 DOT occupation means by 1970 COC and gender.

\footnotetext{
${ }^{1}$ Although the DOT contains over 12,000 occupational titles created originally during the 1930 s, many of these occupations correspond to extraordinarily narrowly defined manufacturing jobs that are no longer represented in employment.
} 
We next required a method to consistently assign these means to COC occupations for 1960,1980 , and 1990.

To generate DOT means by 1960 occupation, we developed a crosswalk from the 1970 to 1960 COC occupational classification schemes using information in Priebe and Greene (1972). Our crosswalk (available on request) provides a set of 211 consistent 1960-1970 occupations that represent the lowest common level of aggregation needed to obtain a consistent occupation series. We applied the 1970 COC means to our 1970 Census sample by occupation and gender and calculated weighted gender-occupation means across the 211 consistent 1960 - 1970 occupational categories. These means provide our DOT task measures for 1960 occupational categories.

To generate DOT means for 1980 and 1990 occupations required an additional step. Because there is not a close correspondence between the 1970 and 1980 COC coding schemes, it was not possible to develop a bridging crosswalk as we did for 1960 - 1970. Instead, we employed a special Census sample prepared for the Committee on Occupational Classification and Analysis chaired by Donald Treiman and kindly supplied to us by Michael Handel. This file contains 122,141 observations from the 1980 Census that have been individually dual coded with both 1970 and 1980 COC occupation codes based on occupational and other demographic infor mation supplied by Census respondents. ${ }^{2}$ To calculate DOT means by 1980 occupation, we merged the 1970 COC-DOT means describe above to the Treiman file by gender and 1970 COC occupation, achieving a 97 percent match rate. We next appended to the Treiman file a set of consistent occupation codes for the years 1980 to 1998 developed by Autor, Katz and Krueger. These codes resolve minor changes to the COC schemes employed in the 1980 and 1990 Censuses and corresponding CPS files. Finally, to form DOT means by 1980 COC, we calculated laborsupply weighted means of each DOT measure within consistent 1980 COC occupation gender categories. These steps provide a set of by-gender DOT means for each of 485 DOT occupations that are consistent for $1980-1998$.

\section{A.3. Computing DOT Task Means by Consistent 1960 - 1998 Industry}

To compute DOT task means overall, by industry, and by industry-education cell for 1960 - 1998, we assigned the consistent DOT occupational task means for $1960-1998$ by gender and occupation to each observation in our Census and CPS samples for 1960 - 1998. Using labor supply in FTEs as weights, we calculated means of each DOT measure for each occupation-industry-education-year cell. These means provide the primary outcome measures for our analysis.

To attain compatibility between changing Census Industry Codes for 1960 - 1998, we use a crosswalk developed by Autor, Katz, and Krueger (1998) providing 140 consistent CIC industries spanning all sectors of the economy. This crosswalk includes all $\mathrm{ClC}$ industrie s and attains consistency by aggregating where necessary to the lowest common level of consistent industry definition among 1970, 1980 and 1990 CIC standards.

\section{A.4. Calculating Within-Occupation Changes in DOT Task Measures: $1977-1991$}

To measure within-occupation changes in task content, we employed the 1991 Revised Fourth Edition of the Dictionary of Occupational Titles (available in electronic form as National Academy of Sciences, 1981). Based on a study of select industries to determine which jobs had undergone the most significant occupational changes since the 1977 publication of the DOT $4^{\text {th }}$ edition, DOT analysts introduced,

\footnotetext{
${ }^{2}$ Hence, 1980 COC codes vary within 1970 COC codes and vice versa in this hand-coded sample.
} 
revised, and eliminated occupational definitions for occupations that were observed to have most substantively changed between 1977 and 1991. In total, 2,452 occupations were reviewed, updated, and/or added. In addition, 646 nominal titles were revised, 136 titles combined, and 75 deleted.

We use the Conversion Tables of Code and Title Changes: Fourth to Revised Fourth Edition Dictionary of Occupational Title, kindly provided by the North Carolina Employment Security Commission, to construct a crosswalk between the 1991 DOT and 1977 DOT occupation codes. Using this crosswalk, we applied the DOT 1991 task variables to our 1971 CPS file, yielding a match rate of over 99.9 percent. Of these matched occupations, 73 percent had been updated between 1977 and 1991 by DOT examiners. We then calculated DOT means by 1970 and 1980 COC occupations and gender using a procedure identical to that described in A.3. Because we use identical procedures for processing both DOT files, the within-occupation variation in DOT task measures that we exploit stems exclusively from re-evaluation of occupational content by DOT examiners, rather than from changes in the relative size of DOT sub-occupations within CIC occupations.

\section{A.5. Composite Task Indicators from the DOT}

To verify that our results are robust to plausible alternative selections of DOT variables, we formed composite indicators of our intended constructs using Principal Components Analysis. As described in the text, we chose a short list of alternative DOT variables that appeared relevant to each of our conceptual categories. These choices are (including our preferred DOT measures):

Non-Routine Cognitive/Analytic Tasks: GED-MATH, GED-REASON, NUMER, INTELL

Non-Routine Cognitive/Interactive Tasks: DCP, GED-LANGUAGE, REPCON (-), AND DEPL

Routine Cognitive Tasks: STS, COLORDIS, MANDEX, AND MVC

Routine Manual Tasks: FINGDEX, MOTOR, FORM

Non-Routine Manual Tasks: EYEHAND, CLERICAL (-), SPATIAL

Note that a (-) sign next to variable means that it was considered to be opposite to the intended construct and hence a suitable candidate for the PCA.

Using these variables (standardized with mean zero and variance one), we performed a PCA for each set to identify the linear combinations that maximized common variation subject to the constraint that the sum of squared vector weights is equal to one. Consistent with our treatment of DOT measures above, we conducted PCAs separately for males and females using the occupation-by-gender data set described in section A.2 and weighting by the occupational distribution of employment in the 1970 Census. In every case, we used the first principal component as the gender- and occupation-specific composite indicator of the task measure. (In almost very case, only the first eigenvector was above one.) To aggregate these task composites to the industry by year level, we followed steps exactly analogous to those used for the non-composited DOT variables. Models that use these composites in place of the direct DOT task measures are found in Panel B of Table 2 and in Appendix Table 5.

\section{A.6. Computer Usage Data from the Current Population Survey}

Industry computer use frequencies were calculated from the October 1984 and 1997 School Enrollment Supplements to the Current Population Survey (CPS) as the weighted fraction of currently employed 
workers ages 18 - 65 who answered yes to the question, "Do you use a computer directly at work?" within consistent $\mathrm{CIC}$ industries. A computer is defined as a desktop terminal or PC with keyboard and monitor and does not include an electronic cash register or a hand held data device. 61,712 and 56,247 observations were used to calculate these frequencies in 1984 and 1997 respectively.

\section{A.7. Computer and Capital Investment Measures from the National Income and Products Accounts}

We used data on capital stock (equipment and structures) and investment in computer equipment from the National Income and Product Accounts (NIPA) to measure capital stock and computer capital holdings at the industry level between 1950 - 1997. To reduce measurement error, all variables in the NIPA were constructed as 5-year centered averages of the respective data category. All NIPA stock and investment variables are measured in real dollars. Deflation of NIPA measures is performed by the Bureau of Economic Analysis using primarily Producer Price Indexes (PPI's). PPI's for computer investment are based on quality adjustment, price linking, and hedonic regression methods. As denominators for capital/FTE and computer investment/FTE variables, we used Census and CPS samples to calculate FTEs by industry by year.

We used two sources of NIPA data to form estimates of capital stock and computer investment. For the years 1950 - 1990, we relied on the 1993 revision of the NIPA (U.S. Department of Commerce, 1993). In this data set, we measure computer investment using the Office Computing and Accounting Machinery (OCAM) variable. Because this NIPA revision set only provides data to 1989, we utilized the as-of-yet incomplete 1999 revision to the NIPA (U.S. Department of Commerce, 1999) to form industry capital stock and computer investment measures for 1990 - 1997. In the 1999 NIPA release, computer investment is calculated as the sum of data on investment in mainframe and personal computers, computer storage devices, and computer peripherals. Because final capital stock measures by industry are not yet available in the 1999 NIPA data, we estimated each industry's capital stock as the sum of all individual asset items by industry by year.

In pairing these two NIPA series, we make every effort to maintain consistency. In particular, we rescale the revised NIPA variables for 1990 such that they are identical in weighted mean to the previous release of the NIPA. We then apply this scaling factor to all NIPA measures from $1990-$ 1998. In addition, we examined the sensitivity of our results to this pairing by re-estimating the NIPA models in Table 6 excluding the years 1990 - 1998 (i.e., the years that use the revised NIPA data). Our results (available on request) are quite insensitive to this exclusion.

To match CPS and Census data to the NIPA, we relied on a crosswak developed by Autor, Katz and Krueger (1998) and revised for this analysis to accommodate small changes in the NIPA sector scheme made during the recent NIPA revision. The resulting aggregation of N1PA and CIC data contains 47 consistent industries covering all industrial sectors excluding Government and Private Households, spanning the 1960 - 1998 CIC standards. Of these 47, we exclude from our analysis agriculture and government dominated services (5 NIPA industries). 

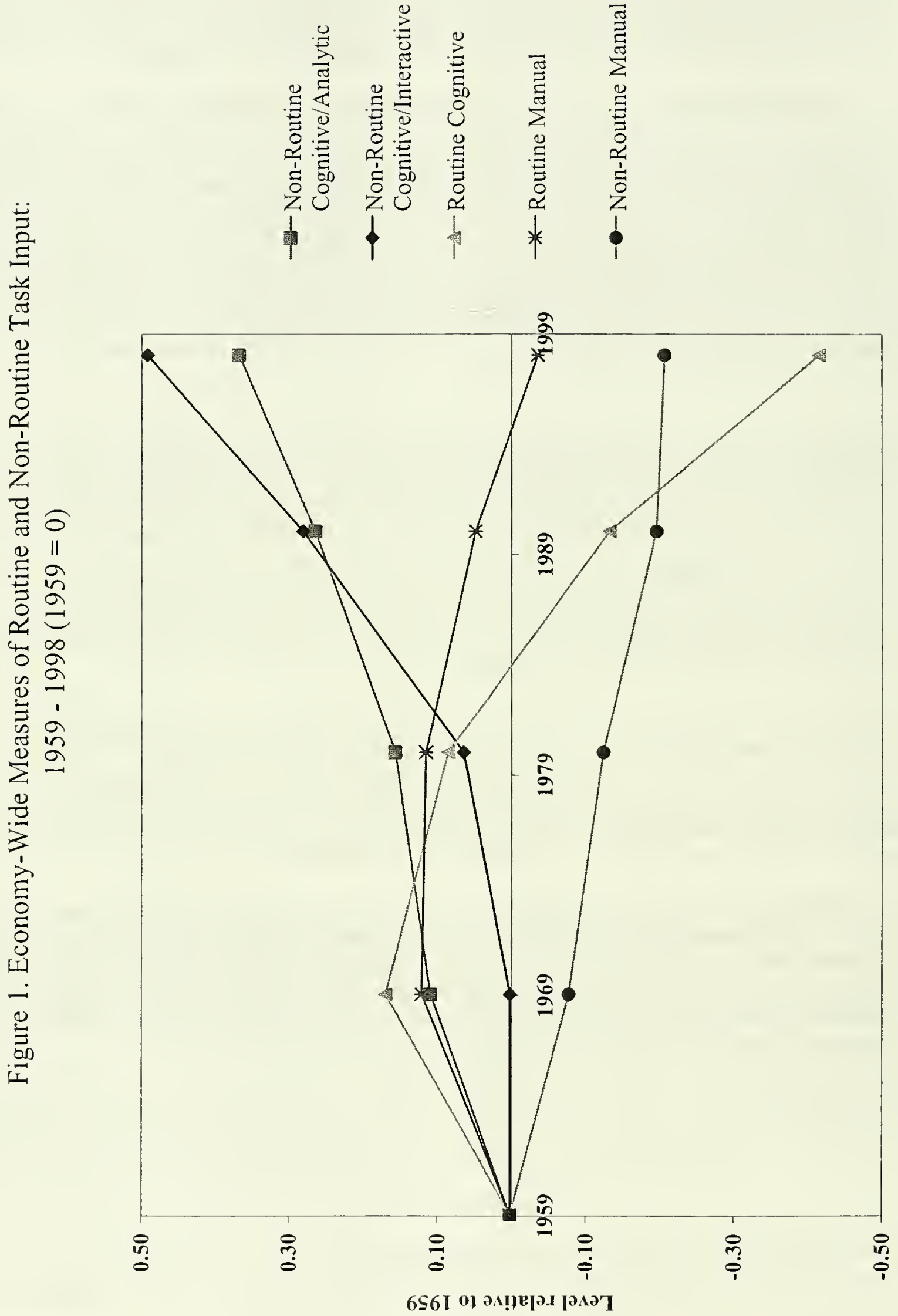


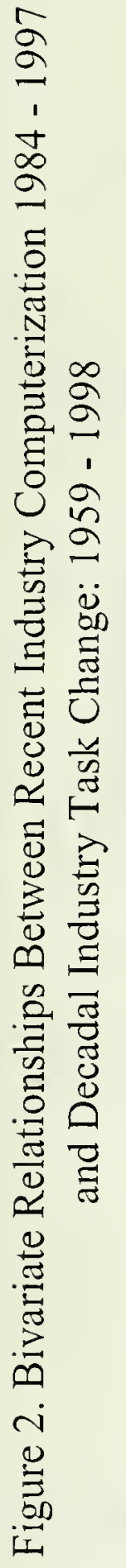

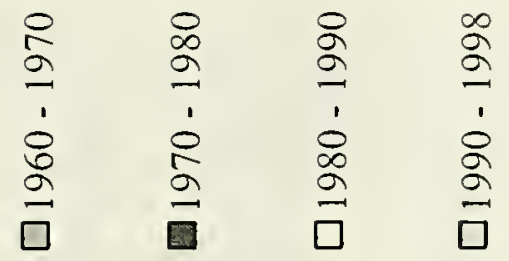

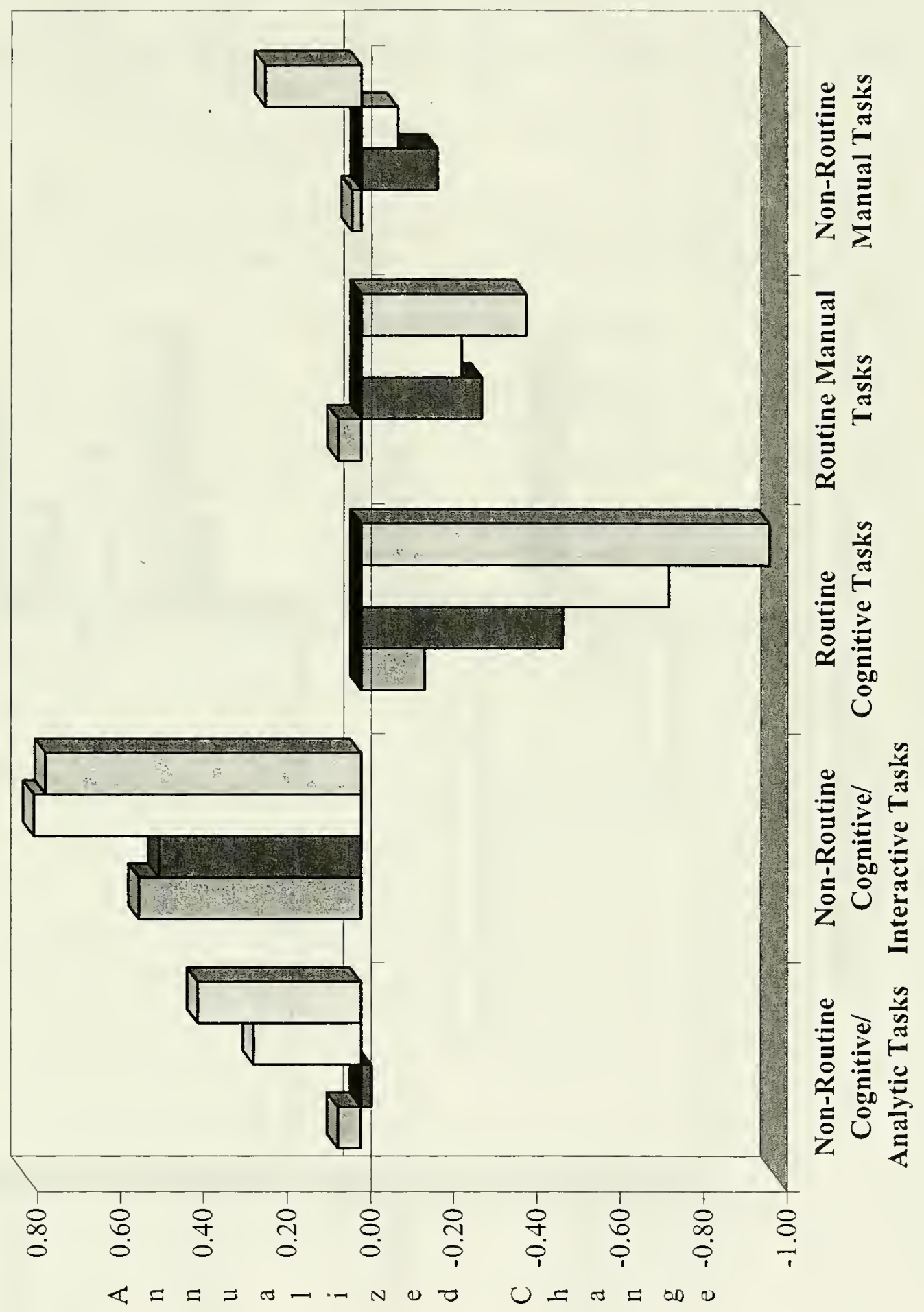



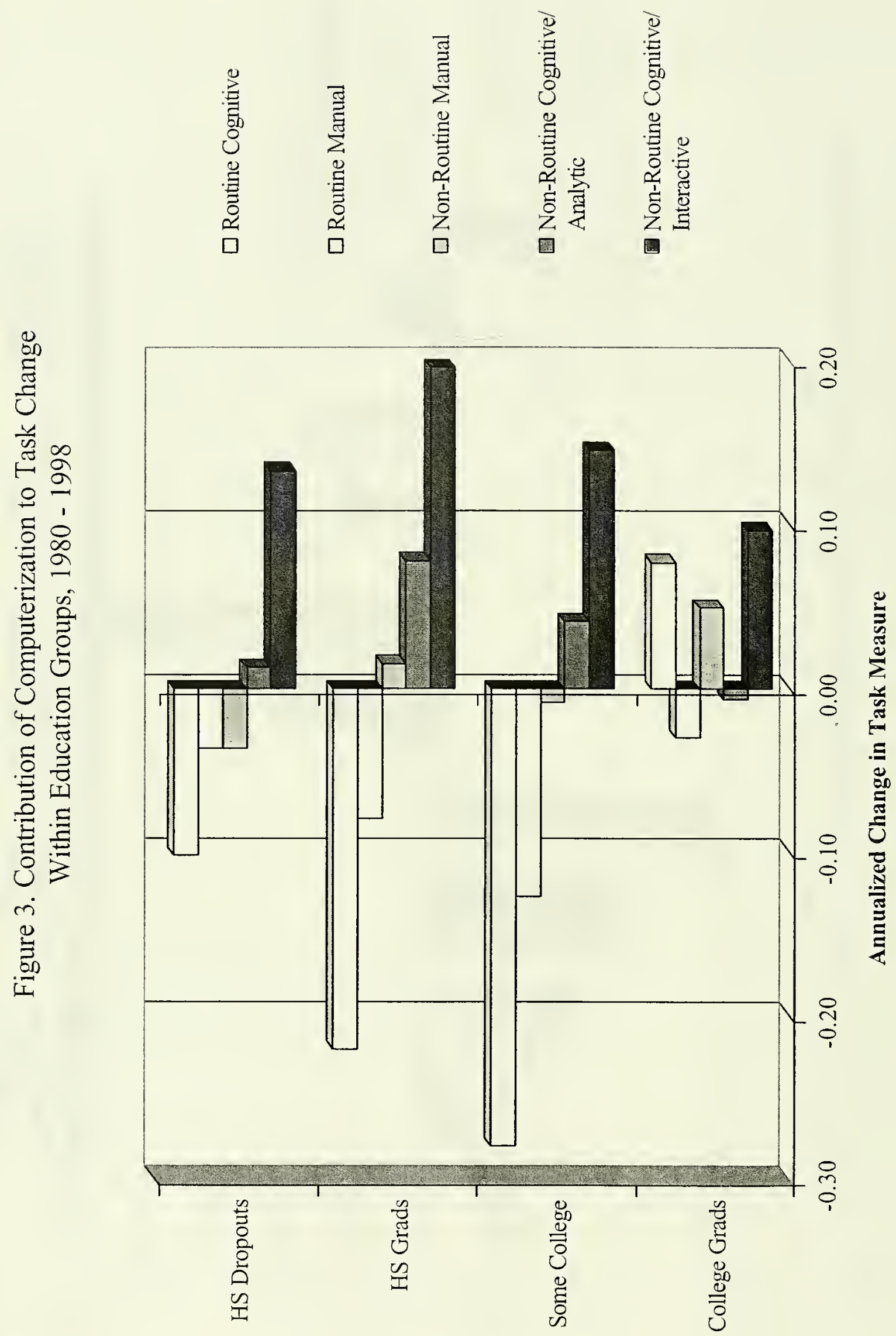
Table 1: Potential Impact of Computerization on Four Categories of Workplace Tasks.

\begin{tabular}{|c|c|c|}
\hline & Routine Tasks & Non-Routine Tasks \\
\hline & A. Vist & Manual \\
\hline \multirow[t]{2}{*}{ Examples } & $\begin{array}{l}\text { - Picking and sorting engineered } \\
\text { objects on an assembly line. }\end{array}$ & - Janitorial services. \\
\hline & $\begin{array}{l}\text { - Reconfiguring production lines } \\
\text { to enable short runs. }\end{array}$ & - Truck driving. \\
\hline \multirow[t]{2}{*}{$\begin{array}{l}\text { Computer } \\
\text { Impact }\end{array}$} & $\begin{array}{l}\text { - Computer control makes capital } \\
\text { substitution feasible. }\end{array}$ & $\begin{array}{l}\text { - Limited opportunities for } \\
\text { substitution or complementarity. }\end{array}$ \\
\hline & \multicolumn{2}{|c|}{ B. Information Processing/Cognitive } \\
\hline Examples & $\begin{array}{l}\text { - Bookkeeping; } \\
\text { - Filing/retrieving textual data; } \\
\text { - Processing procedural } \\
\text { interactions/ transactions (e.g., } \\
\text { bank teller) }\end{array}$ & $\begin{array}{l}\text { - Medical diagnosis; } \\
\text { - Legal writing; } \\
\text { - Persuading/selling. }\end{array}$ \\
\hline
\end{tabular}

\section{Computer}

Impact

- Substantial substitution.

- Strong complementarities. 
Table 2: The Impact of Industry Task Content in 1959 on Industry Computer Adoption between 1959 and 1997.

Dependent Variable: Percentage of Industry Employees Using a Computer on the Job in 1997

\begin{tabular}{|c|c|c|c|c|}
\hline 1. Non-Routir & Non-Routi & & & \\
\hline $\begin{array}{c}\text { Cognitive/ } \\
\text { Analytic }\end{array}$ & $\begin{array}{l}\text { Cognitive/ } \\
\text { Interactive }\end{array}$ & $\begin{array}{l}\text { 3. Routine } \\
\text { Cognitive }\end{array}$ & $\begin{array}{l}\text { 4. Routine } \\
\text { Manual }\end{array}$ & $\begin{array}{l}\text { 5. Non-Routine } \\
\text { Manual }\end{array}$ \\
\hline
\end{tabular}

A. Specifications Using Individual DOT Task Measures

$\begin{array}{cccccc}\text { (1) 1959 DOT Industy } & 9.94 & -2.09 & 5.52 & 8.16 & -10.13 \\ \begin{array}{c}\text { Task Measure } \\ \text { (1.70) }\end{array} & (1.89) & (1.84) & (1.77) & (1.69) \\ \mathbf{R}^{2} & 0.20 & 0.01 & 0.06 & 0.13 & 0.21\end{array}$

(2) 1959 DOT Industy

$\begin{array}{ccccc}6.37 & -3.89 & 6.43 & 6.60 & -8.06 \\ (1.89) & (1.68) & (1.61) & (1.62) & (1.61)\end{array}$

Task Measure

(1.89)

(1.68)

(1.61) $-(1.62)$

1959 Industry

7.00

10.89

10.78

9.12

8.22

College Grad.

(1.89)

(1.68)

(1.61)

(1.62)

(1.61)

$$
\mathbf{R}^{2}
$$

0.27

0.24

0.29

0.30

0.33

B. Specifications Using Alternative Composite DOT Task Measures

(3)

1959 Industry
Task Composite

$$
\mathrm{R}^{2}
$$

(4) 1959 Industry

Task Composite

1959 Industry

College Grad.

$$
\mathbf{R}^{2}
$$

13.59

(1.50)

8.04

(1.77)

$-0.66$

(1.90)

5.86

(1.83)

0.00

0.07

1.70

4.96

(1.64)

(2.14)

(2.06)

(1.73)

8.40

10.62

(1.73)

9.79

(1.64)

(2.14)

(2.06)

0.37

0.22

0.22

0.26

$-13.59$

0.37

$-11.41$

6.28

(1.52)

$n$ is 140 consistent 3 -digit CIC occupations. DOT industry means are calculated using 1960 Census IPUMS and DOT 1977 job content measures. To aid comparison between panels A and B, all DOT and composite variables are standardized with mean zero and variance one. Mean of dependent variable is 45.4 percentage points. Industry computer use 1997 calculated from October 1997 CPS. Details of construction of composite DOT measures are provided in the Data Appendix. 
Table 3. Means of Dictionary of Occupational Titles Job Task Measures:

Overall and by Gender, 1960 - 1998.

Task Measure

\begin{tabular}{lcccc}
\hline $\begin{array}{l}\text { 1. Non-Routine } \\
\text { Cognitive/ }\end{array}$ & $\begin{array}{c}\text { 2. Non-Routine } \\
\text { Cognitive/ } \\
\text { Analytic }\end{array}$ & $\begin{array}{c}\text { 3. Routine } \\
\text { Interactive }\end{array}$ & $\begin{array}{c}\text { 4. Routine } \\
\text { Cognitive }\end{array}$ & Manual
\end{tabular} $\begin{gathered}\text { 5. Non-Routine } \\
\text { Manual }\end{gathered}$

\section{A. Overall}

$\begin{array}{llllll}\text { Census 1960 } & 3.61 & 2.40 & 4.53 & 3.78 & 1.37 \\ \text { Census 1970 } & 3.72 & 2.40 & 4.70 & 3.90 & 1.29 \\ \text { CPS 1980 } & 3.76 & 2.46 & 4.61 & 3.90 & 1.24 \\ \text { CPS 1990 } & 3.87 & 2.68 & 4.40 & 3.83 & 1.17 \\ \text { CPS 1998 } & 3.97 & 2.89 & 4.11 & 3.75 & 1.16\end{array}$

\section{B. Males and Females}

Male Female Male Female Male Female Male Female $\stackrel{\text { Male Female }}{\text { Male }}$

$\begin{array}{lllllllllll}\text { Census 1960 } & 3.81 & 3.05 & 2.82 & 1.20 & 4.43 & 4.81 & 3.60 & 4.29 & 1.56 & 0.82 \\ \text { Census 1970 } & 3.93 & 3.23 & 2.91 & 1.27 & 4.51 & 5.12 & 3.64 & 4.48 & 1.50 & 0.80 \\ \text { CPS 1980 } & 3.95 & 3.46 & 2.94 & 1.71 & 4.47 & 4.84 & 3.62 & 4.34 & 1.55 & 0.74 \\ \text { CPS 1990 } & 3.99 & 3.70 & 2.99 & 2.25 & 4.36 & 4.45 & 3.60 & 4.14 & 1.49 & 0.72 \\ \text { CPS 1998 } & 4.07 & 3.84 & 3.10 & 2.62 & 4.24 & 3.95 & 3.58 & 3.97 & 1.48 & 0.73\end{array}$

Sources: All employed workers ages 18 - 64, Census IPUMS 1960 and 1970, CPS MORG 1980, 1990, and 1998, and Dictionary of Occupational Titles 1977. See Data Appendix for details. 
Table 4. Between- and Within- Industry Decomposition of the Change in Skill Use: 1960 - 1998: Dependent Variable is $10 \times$ (Annualized Change in DOT Task Measure).

\section{Task Measure}

\begin{tabular}{|c|c|c|c|c|c|}
\hline Data Source & $\begin{array}{l}\text { 1. Non- } \\
\text { Routine } \\
\text { Cognitive/ } \\
\text { Analytic }\end{array}$ & $\begin{array}{l}\text { 2. Non- } \\
\text { Routine } \\
\text { Cognitive/ } \\
\text { Interactive }\end{array}$ & $\begin{array}{l}\text { 3. Routine } \\
\text { Cognitive }\end{array}$ & $\begin{array}{l}\text { 4. Routine } \\
\text { Manual }\end{array}$ & $\begin{array}{l}\text { 5. Non- } \\
\text { Routine } \\
\text { Manual }\end{array}$ \\
\hline
\end{tabular}

$\begin{array}{llllll}1960-70 \text { Census-Census } & 0.107 & 0.005 & 0.166 & 0.119 & -0.079 \\ 1970-80 \text { Census-Census } & 0.095 & 0.114 & 0.000 & 0.014 & -0.076 \\ 1980-90 \text { CPS-CPS } & 0.108 & 0.215 & -0.219 & -0.067 & -0.071 \\ 1990-98 \text { CPS-CPS } & 0.130 & 0.266 & -0.353 & -0.105 & -0.014\end{array}$

\section{B. Between- and Within-Industry Components}

Btwn Wthin Btwn Wthin Btwn Wthin Btwn Wthin Btwn Wthin

\begin{tabular}{|c|c|c|c|c|c|c|c|c|c|c|c|}
\hline $1960-70$ & Census-Census & 0.078 & 0.029 & -0.056 & 0.061 & 0.088 & 0.077 & 0.068 & 0.051 & -0.062 & -0.017 \\
\hline 1970 - & Census-Census & 0.069 & 0.026 & 0.002 & 0.112 & 0.033 & -0.033 & 0.024 & -0.010 & -0.031 & -0.045 \\
\hline 1980 & CPS-CPS & 0.040 & 0.068 & 0.017 & 0.198 & -0.100 & -0.118 & -0.001 & -0.066 & -0.034 & -0.037 \\
\hline $1990-98$ & CPS-CPS & 0.025 & 0.105 & 0.028 & 0.238 & -0.100 & -0.253 & -0.009 & -0.097 & -0.004 & -0.010 \\
\hline
\end{tabular}

Shift-share analysis based on 140 CIC industries made consistent for 1960 - 1998. Samples are constructed for all employed workers from Census and CPS samples listed above. All calculations weighted by labor supply in FTEs (product of sample weight and annual hours worked). Observations use DOT 1977 occupational task content measures paired to Census and CPS samples. See Data Appendix for further details. 
Table 5. OLS Estimates of the Relationship between Industry Computerization and Industry

Task Input, 1960 - 1998. Dependent Variables: $10 \mathrm{x}$ (Annual Change in Task Measure)

\begin{tabular}{|c|c|c|c|c|c|}
\hline Task Measure & Estimate & A. $1960-70$ & B. $1970-80$ & C. $1980-90$ & D. $1990-98$ \\
\hline 1. $\Delta$ Non-Routine & $\Delta$ Computer & 0.055 & -0.025 & 0.257 & 0.390 \\
\hline \multirow[t]{5}{*}{ Cognitive/ Analytic } & $1984-97$ & $(0.147)$ & $(0.132)$ & $(0.143)$ & $(0.156)$ \\
\hline & Intercept & 0.016 & 0.032 & 0.003 & 0.005 \\
\hline & & $(0.038)$ & $(0.035)$ & $(0.039)$ & $(0.043)$ \\
\hline & $\mathbf{R}^{2}$ & 0.00 & 0.00 & 0.02 & 0.04 \\
\hline & Mean Task $\Delta$ & 0.029 & 0.026 & 0.068 & 0.105 \\
\hline 2. $\Delta$ Non-Routine & $\Delta$ Computer & 0.532 & 0.483 & 0.786 & 0.758 \\
\hline \multirow[t]{5}{*}{ Cognitive/ Interactive } & $1984-97$ & $(0.239)$ & $(0.257)$ & $(0.276)$ & $(0.258)$ \\
\hline & Intercept & -0.066 & -0.008 & 0.000 & 0.043 \\
\hline & & $(0.062)$ & $(0.069)$ & $(0.075)$ & $(0.071)$ \\
\hline & $\mathbf{R}^{2}$ & 0.03 & 0.03 & 0.06 & 0.06 \\
\hline & Mean Task $\Delta$ & 0.061 & 0.112 & 0.198 & 0.238 \\
\hline \multirow[t]{6}{*}{ 3. $\Delta$ Routine Cognitive } & $\Delta$ Computer & -0.152 & -0.485 & -0.740 & -0.980 \\
\hline & $1984-97$ & $(0.238)$ & $(0.289)$ & $(0.309)$ & $(0.294)$ \\
\hline & Intercept & 0.114 & 0.087 & 0.068 & -0.002 \\
\hline & & $(0.062)$ & $(0.077)$ & $(0.083)$ & $(0.080)$ \\
\hline & $\mathrm{R}^{2}$ & 0.00 & 0.02 & 0.04 & 0.07 \\
\hline & Mean Task $\Delta$ & 0.077 & -0.033 & -0.118 & -0.253 \\
\hline \multirow[t]{6}{*}{ 4. $\Delta$ Routine Manual } & $\Delta$ Computer & 0.055 & -0.290 & -0.241 & -0.397 \\
\hline & $1984-97$ & $(0.081)$ & $(0.101)$ & $(0.128)$ & $(0.114)$ \\
\hline & Intercept & 0.038 & 0.062 & -0.005 & 0.005 \\
\hline & & $(0.021)$ & $(0.027)$ & $(0.035)$ & $(0.031)$ \\
\hline & $\mathbf{R}^{2}$ & 0.00 & 0.06 & 0.03 & 0.08 \\
\hline & Mean Task $\Delta$ & 0.051 & -0.010 & -0.066 & -0.097 \\
\hline \multirow{6}{*}{$\begin{array}{l}\text { 5. } \Delta \text { Non-Routine } \\
\text { Manual }\end{array}$} & $\Delta$ Computer & 0.022 & -0.183 & -0.087 & 0.230 \\
\hline & $1984-97$ & $(0.064)$ & $(0.114)$ & $(0.105)$ & $(0.079)$ \\
\hline & Intercept & -0.022 & 0.001 & -0.015 & -0.069 \\
\hline & & $(0.017)$ & $(0.030)$ & $(0.028)$ & $(0.022)$ \\
\hline & $\mathrm{R}^{2}$ & 0.00 & 0.02 & 0.00 & 0.06 \\
\hline & Mean Task $\Delta$ & -0.017 & -0.045 & -0.037 & -0.010 \\
\hline
\end{tabular}

$n$ is 140 consistent CIC industries. Standard errors are in parentheses. Weighted mean of $\Delta$ computer use 1984 1997 is 0.252 . Estimates are weighted by mean industry share of total employment (in FTEs) over the endpoints of the years used to form the dependent variable. Computer use is the change in fraction of industry workers using a computer at their jobs estimated from October 1984 and 1997 CPS samples. Samples used are Census IPUMS for 1960, 70, and 80 and CPS MORG 1980, 90, and 98 samples. 
Task Measure

\begin{tabular}{|c|c|c|c|c|}
\hline $\begin{array}{l}\text { 1. } \Delta \text { Non-Routine } \\
\text { Cognitive/ } \\
\text { Analytic }\end{array}$ & $\begin{array}{c}\text { 1. } \Delta \text { Non-Routine } \\
\text { Cognitive/ } \\
\text { Interactive }\end{array}$ & $\begin{array}{l}\text { 3. } \Delta \text { Routine } \\
\text { Cognitive }\end{array}$ & $\begin{array}{l}\text { 4. } \Delta \text { Routine } \\
\text { Manual }\end{array}$ & $\begin{array}{c}\text { 5. } \Delta \text { Non-Routine } \\
\text { Manual }\end{array}$ \\
\hline (1) (2) & (3) (4) & (5) (6) & (7) & $(10)$ \\
\hline
\end{tabular}

\begin{tabular}{|c|c|c|c|c|c|c|c|c|c|c|}
\hline $\log (\mathrm{CI} / \mathrm{L})$ & $\begin{array}{r}0.228 \\
(0.091)\end{array}$ & $\begin{array}{r}0.202 \\
(0.106)\end{array}$ & $\begin{array}{r}0.854 \\
(0.244)\end{array}$ & $\begin{array}{r}0.822 \\
(0.245)\end{array}$ & $\begin{array}{r}-0.676 \\
(0.204)\end{array}$ & $\begin{array}{r}-0.623 \\
(0.187)\end{array}$ & $\begin{array}{r}-0.328 \\
(0.086)\end{array}$ & $\begin{array}{r}-0.275 \\
(0.070)\end{array}$ & $\begin{array}{r}0.254 \\
(0.043)\end{array}$ & $\begin{array}{r}0.201 \\
(0.049)\end{array}$ \\
\hline$\Delta \log (\mathrm{K} / \mathrm{L})$ & & $\begin{array}{r}0.033 \\
(0.056)\end{array}$ & & $\begin{array}{r}0.041 \\
(0.133)\end{array}$ & & $\begin{array}{r}-0.069 \\
(0.109)\end{array}$ & & $\begin{array}{r}-0.068 \\
(0.040)\end{array}$ & & $\begin{array}{r}0.068 \\
(0.028)\end{array}$ \\
\hline $1970-80$ & $\begin{array}{l}-0.027 \\
(0.035)\end{array}$ & $\begin{array}{r}-0.020 \\
(0.035)\end{array}$ & $\begin{array}{r}0.002 \\
(0.067)\end{array}$ & $\begin{array}{r}0.011 \\
(0.066)\end{array}$ & $\begin{array}{r}-0.040 \\
(0.094)\end{array}$ & $\begin{array}{r}-0.055 \\
(0.091)\end{array}$ & $\begin{array}{r}-0.019 \\
(0.022)\end{array}$ & $\begin{array}{r}-0.034 \\
(0.022)\end{array}$ & $\begin{array}{l}-0.044 \\
(0.016)\end{array}$ & $\begin{array}{r}-0.028 \\
(0.018)\end{array}$ \\
\hline $1980-90$ & $\begin{array}{l}-0.032 \\
(0.048)\end{array}$ & $\begin{array}{r}-0.018 \\
(0.050)\end{array}$ & $\begin{array}{r}-0.132 \\
(0.117)\end{array}$ & $\begin{array}{r}-0.114 \\
(0.103)\end{array}$ & $\begin{array}{r}-0.002 \\
(0.116)\end{array}$ & $\begin{array}{r}-0.032 \\
(0.122)\end{array}$ & $\begin{array}{r}-0.024 \\
(0.031)\end{array}$ & $\begin{array}{r}-0.054 \\
(0.036)\end{array}$ & $\begin{array}{r}-0.106 \\
(0.021)\end{array}$ & $\begin{array}{c}-0.076 \\
(0.022)\end{array}$ \\
\hline $1990-98$ & $\begin{array}{r}-0.035 \\
(0.047)\end{array}$ & $\begin{array}{r}-0.020 \\
(0.053)\end{array}$ & $\begin{array}{r}-0.141 \\
(0.108)\end{array}$ & $\begin{array}{r}-0.123 \\
(0.105)\end{array}$ & $\begin{array}{r}-0.041 \\
(0.111)\end{array}$ & $\begin{array}{r}-0.072 \\
(0.111)\end{array}$ & $\begin{array}{r}-0.012 \\
(0.039)\end{array}$ & $\begin{array}{r}-0.042 \\
(0.039)\end{array}$ & $\begin{array}{r}-0.104 \\
(0.023)\end{array}$ & $\begin{array}{r}-0.074 \\
(0.027)\end{array}$ \\
\hline Intercept & $\begin{array}{r}0.152 \\
(0.050)\end{array}$ & $\begin{array}{r}0.127 \\
(0.062)\end{array}$ & $\begin{array}{r}0.473 \\
(0.119)\end{array}$ & $\begin{array}{r}0.443 \\
(0.127)\end{array}$ & $\begin{array}{r}-0.236 \\
(0.116)\end{array}$ & $\begin{array}{c}-0.185 \\
(0.111)\end{array}$ & $\begin{array}{c}-0.102 \\
(0.044)\end{array}$ & $\begin{array}{c}-0.052 \\
(0.037)\end{array}$ & $\begin{array}{r}0.106 \\
(0.023)\end{array}$ & $\begin{array}{r}0.056 \\
(0.031)\end{array}$ \\
\hline
\end{tabular}

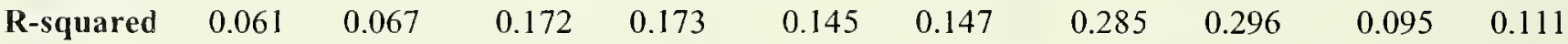

\section{Mean $\triangle$ Dep. Variable}

$\begin{array}{llllll}\mathbf{1 9 6 0 - 7 0} & 0.042 & 0.064 & 0.089 & 0.055 & -0.015 \\ \mathbf{1 9 7 0 - 8 0} & 0.038 & 0.151 & -0.019 & 0.003 & -0.033 \\ \mathbf{1 9 8 0 - 9 0} & 0.080 & 0.195 & -0.122 & -0.070 & -0.043 \\ \mathbf{1 9 9 0 - 9 8} & 0.096 & 0.255 & -0.216 & -0.084 & -0.021\end{array}$

$n$ is $492: 123$ consistent $\mathrm{CIC}$ industries times 4 decade changes. Standard errors in parentheses are

heteroskedasticity consistent and allow for clustering of errors within NIPA-year sectors (42 clusters per decade). Private households, govermment, and government-dominated services are excluded due to NIPA data limitations. 1960-70, 70-80 use Census IPUMS samples, and 1980-90 and 1990-98 use CPS MORG samples. $\log (\mathrm{CI} / \mathrm{L})$ is $0.1 * \log$ computer investment per FTE over decade in 1,000 s of $1987 \$ . \Delta \log (\mathrm{K} / \mathrm{L})$ is annualized change in the $\log$ capital/FTE ratio over deacde. Weighted mean of $\log (\mathrm{CI} / \mathrm{L})$ is $-0.480 \mathrm{in} 1960-1970,-0.379$ in 1970-1980, 0.172 in 1980-90, and -0.91 in 1990-97. Weighted mean of $\Delta(\mathrm{K} / \mathrm{L}) \log$ capital per worker is 0.439 in 1960-1970, $0.0991970-1980,0.100$ in 1980-90, and 0.222 in 1990-98. Estimates are weighted by mean industry share of total employment (in FTEs) over the endpoints of the years used to form the dependent variable. 
Table 7. OLS Estimates of the Impact of Industry Computerization on Industry Task Input Overall and among High School Graduates, 1980 - 98. Dependent variable: $10 \mathrm{x}$ (Annualized Change in DOT Task Measure)

Task Measure

\begin{tabular}{ccccc}
\hline 1. $\Delta$ Non- & 2. $\Delta$ Non- & & \\
Routine & Routine & & $5 . \Delta$ Non- \\
Cognitive/ & Cognitive/ & 3. $\Delta$ Routine & $4 . \Delta$ Routine & Routine \\
Analytic & Interactive & Cognitive & Manual & Manual \\
\hline
\end{tabular}

\section{A. Overall Within-Industry Task Shifts}

\begin{tabular}{|c|c|c|c|c|c|}
\hline $\begin{array}{l}\Delta \text { Computer } \\
\text { Use '84-'97 }\end{array}$ & $\begin{array}{c}0.400 \\
(0.154)\end{array}$ & $\begin{array}{c}1.008 \\
(0.268)\end{array}$ & $\begin{array}{l}-1.128 \\
(0.321)\end{array}$ & $\begin{array}{l}-0.402 \\
(0.137)\end{array}$ & $\begin{array}{c}0.080 \\
(0.086)\end{array}$ \\
\hline Intercept & $\begin{array}{c}0.004 \\
(0.032)\end{array}$ & $\begin{array}{c}0.016 \\
(0.056)\end{array}$ & $\begin{array}{c}0.043 \\
(0.067)\end{array}$ & $\begin{array}{c}0.000 \\
(0.029)\end{array}$ & $\begin{array}{l}-0.041 \\
(0.018)\end{array}$ \\
\hline Mean $\Delta$ & 0.082 & 0.212 & -0.177 & -0.079 & -0.026 \\
\hline $\mathbf{R}^{2}$ & 0.046 & 0.093 & 0.082 & 0.058 & 0.006 \\
\hline
\end{tabular}

\section{B. Within-Industry Task Shifts Among High School Graduates}

$\begin{array}{lccccc}\Delta \text { Computer } & -0.011 & 0.796 & -2.297 & -0.833 & 0.056 \\ \text { Use '84-'97 } & (0.134) & (0.259) & (0.396) & (0.154) & (0.108) \\ \text { Intercept } & -0.039 & -0.037 & 0.162 & 0.019 & 0.001 \\ & (0.028) & (0.054) & (0.082) & (0.032) & (0.023) \\ \text { Mean } \Delta & -0.041 & 0.118 & -0.286 & -0.144 & 0.012 \\ \mathbf{R}^{2} & & & & & \\ & 0.000 & 0.064 & 0.197 & 0.176 & 0.002\end{array}$

$n$ is 140 consistent CIC industries. Standard errors are in parentheses. Computer use is measured as ten times the change in industry computer use frequency from the 1984 and 1997 CPS (weighted mean 0.198). Dependent variables formed from CPS MORG 1980 and 1998 samples using DOT 1977 occupational task content measures. Models are weighted by mean industry share of total employment (in FTEs) over the endpoints of the years used to form the dependent variable. 
Table 8. Contribution of Computerization to Task Upgrading

Within and Between Education Groups, 1980 - 1998.

Dependent Variable: $10 \times$ (Annualized Within-Industry Change in DOT Task Measure)

\begin{tabular}{|c|c|c|c|c|c|c|c|c|c|c|}
\hline \multirow[b]{2}{*}{ Overall change 80 - 98} & \multicolumn{2}{|c|}{$\begin{array}{l}\text { 1. } \Delta \text { Non- } \\
\text { Routine } \\
\text { Cognitive/ } \\
\text { Analytic }\end{array}$} & \multicolumn{2}{|c|}{$\begin{array}{l}\text { 2. } \Delta \text { Non- } \\
\text { Routine } \\
\text { Cognitive/ } \\
\text { Interactive }\end{array}$} & \multicolumn{2}{|c|}{$\begin{array}{l}\text { 3. } \Delta \text { Routine } \\
\text { Cognitive }\end{array}$} & \multicolumn{2}{|c|}{$\begin{array}{l}\text { 4. } \Delta \text { Routine } \\
\text { Manual }\end{array}$} & \multicolumn{2}{|c|}{$\begin{array}{c}\text { 5. } \Delta \text { Non- } \\
\text { Routine } \\
\text { Manual }\end{array}$} \\
\hline & 0.152 & $100 \%$ & 0.388 & $100 \%$ & -0.321 & $100 \%$ & -0.143 & $100 \%$ & -0.045 & $100 \%$ \\
\hline Due to computerization & 0.143 & $94 \%$ & 0.359 & $93 \%$ & -0.402 & $125 \%$ & -0.143 & $100 \%$ & 0.029 & $-64 \%$ \\
\hline Within education groups & 0.069 & $45 \%$ & 0.269 & $69 \%$ & -0.258 & $81 \%$ & -0.131 & $91 \%$ & 0.019 & $-43 \%$ \\
\hline HS dropouts & 0.003 & $2 \%$ & 0.034 & $9 \%$ & -0.026 & $8 \%$ & -0.009 & $6 \%$ & -0.009 & $20 \%$ \\
\hline HS graduates & 0.050 & $33 \%$ & 0.125 & $32 \%$ & -0.141 & $44 \%$ & -0.051 & $35 \%$ & 0.010 & $-22 \%$ \\
\hline Some college & 0.019 & $12 \%$ & 0.066 & $17 \%$ & -0.126 & $39 \%$ & -0.057 & $40 \%$ & -0.004 & $9 \%$ \\
\hline College plus & -0.003 & $-2 \%$ & 0.044 & $11 \%$ & 0.035 & $-11 \%$ & -0.014 & $10 \%$ & 0.022 & $-50 \%$ \\
\hline Between education grouf & 0.074 & $49 \%$ & 0.090 & $23 \%$ & -0.144 & $45 \%$ & -0.013 & $9 \%$ & 0.009 & $-21 \%$ \\
\hline
\end{tabular}

The dependent variable is ten times the annualized within-industry change in each measure of task input. The component due to computerization is calculated using regression estimates from Table 7 and Appendix Table 6. Two columns of figures are provided for each task measure. The left hand column displays displays the annualized change measure and the right hand column displays the percentage of the overall change explained. 
Table 9. OLS Estimates of Relationship Between Changes in Dictionary of Occupational Titles Task Content Measures 1977 - 1991 and Occupational Computerization 1984 - 1997. Dependent Variable: $10 \times$ (Annualized Within-Occupation Change in Task Measure)

Task measure

\begin{tabular}{|c|c|c|c|c|c|c|c|c|c|}
\hline \multicolumn{2}{|c|}{$\begin{array}{l}\text { 1. } \Delta \text { Non- } \\
\text { Routine } \\
\text { Cognitive/ } \\
\text { Analytic }\end{array}$} & \multicolumn{2}{|c|}{$\begin{array}{l}\text { 2. } \Delta \text { Non- } \\
\text { Routine } \\
\text { Cognitive/ } \\
\text { Interactive }\end{array}$} & \multicolumn{2}{|c|}{$\begin{array}{l}\text { 3. } \Delta \text { Routine } \\
\text { Cognitive }\end{array}$} & \multicolumn{2}{|c|}{$\begin{array}{l}\text { 4. } \Delta \text { Routine } \\
\text { Motor }\end{array}$} & \multicolumn{2}{|c|}{$\begin{array}{l}\text { 5. } \Delta \text { Non- } \\
\text { Routine } \\
\text { Motor }\end{array}$} \\
\hline (a) & (b) & (a) & (b) & (a) & (b) & (a) & (b) & (a) & (b) \\
\hline $\begin{array}{r}0.30 \\
(0.12)\end{array}$ & $\begin{array}{r}0.33 \\
(0.12)\end{array}$ & $\begin{array}{r}0.96 \\
(0.36)\end{array}$ & $\begin{array}{r}0.97 \\
(0.36)\end{array}$ & $\begin{array}{r}-2.96 \\
(0.54)\end{array}$ & $\begin{array}{r}-3.07 \\
(0.54)\end{array}$ & $\begin{array}{r}0.04 \\
(0.12)\end{array}$ & $\begin{array}{r}0.06 \\
(0.12)\end{array}$ & $\begin{array}{r}0.27 \\
(0.12)\end{array}$ & $\begin{array}{r}0.28 \\
(0.12)\end{array}$ \\
\hline
\end{tabular}

$\begin{array}{lrrrrr}\Delta \text { College Grad } & -0.57 & -0.14 & 2.35 & -0.42 & -0.10 \\ \text { Emp. Share 84-97 } & (0.34) & (1.04) & (1.57) & (0.35) & (0.35)\end{array}$

$\begin{array}{lrrrrrrrrrr}\text { Intercept } & -0.09 & -0.08 & -0.08 & -0.08 & 0.13 & 0.11 & -0.02 & -0.02 & -0.12 & -0.12 \\ & (0.03) & (0.03) & (0.08) & (0.08) & (0.12) & (0.12) & (0.03) & (0.03) & (0.03) & (0.03)\end{array}$

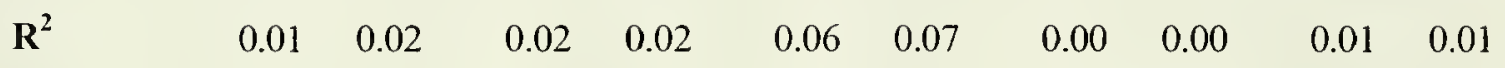

$\begin{array}{llllll}\text { Wtd. Mean } & -0.03 & 0.09 & -0.40 & -0.02 & -0.07\end{array}$

Dep. Var.

Notes. $\mathrm{n}$ is 470 consistent 3-digit CIC occupations. Dependent variable is the change in the occupational DOT skill content measure between the DOT 1977 and DOT 1991 revisions. Computer use and college graduate employment are measured as ten times the change in occupational computer use and collegeplus graduate frequencies from the 1984 and 1997 CPS (weighted means 0.181 and .018 respectively). Estimates are weighted by the occupational share of employment in 1984. 
Table 10. Demand Shift Calculations: Estimated Change in Log College vs. Non-College Relative Demand Due to Task Shifts Induced by Computerization: $1970-1998$.

A. Change in DOT task input measures predicted by computerization (from Tables 6, 7 and 9)

\begin{tabular}{|c|c|c|c|c|c|c|c|}
\hline \multirow[b]{3}{*}{ Task measure } & \multicolumn{4}{|c|}{ Extensive margin } & \multirow{3}{*}{$\begin{array}{c}\text { Intensive } \\
\text { Margin } \\
80-98 \\
\end{array}$} & \multicolumn{2}{|c|}{ Sum } \\
\hline & \multicolumn{3}{|c|}{ NIPA Data } & \multirow{2}{*}{$\frac{\text { CPS Data }}{80-98}$} & & \multirow[b]{2}{*}{$70-98$} & \multirow[b]{2}{*}{$80-98$} \\
\hline & $70-80$ & $80-90$ & $90-98$ & & & & \\
\hline 1. N.R. Cognitive/Interactivt & 0.086 & 0.263 & 0.266 & 0.359 & 0.405 & 1.020 & 0.764 \\
\hline 2. N.R. Cognitive/Analytic & 0.023 & 0.070 & 0.071 & 0.143 & 0.126 & 0.290 & 0.268 \\
\hline 3. Routine Cognitive & -0.068 & -0.208 & -0.211 & -0.402 & -1.246 & -1.733 & -1.648 \\
\hline 4. Routine Manual & -0.033 & -0.101 & -0.102 & -0.143 & 0.016 & -0.220 & -0.128 \\
\hline 5. Non-Routine Manual & 0.019 & 0.070 & 0.074 & 0.029 & 0.116 & 0.278 & 0.144 \\
\hline
\end{tabular}

B. Predicted change in college share of employment (in percentage points)

\begin{tabular}{|c|c|c|c|c|c|c|c|}
\hline \multirow[b]{3}{*}{ Task measure } & \multicolumn{4}{|c|}{ Extensive margin } & \multirow{3}{*}{$\begin{array}{c}\begin{array}{c}\text { Intensive } \\
\text { Margin }\end{array} \\
\mathbf{8 0}-98 \\
\end{array}$} & \multicolumn{2}{|c|}{ Sum } \\
\hline & \multicolumn{3}{|c|}{ NIPA Data } & \multirow{2}{*}{$\begin{array}{l}\text { CPS Data } \\
80-98 \\
\end{array}$} & & \multirow[b]{2}{*}{$70-98$} & \multirow[b]{2}{*}{$80-98$} \\
\hline & $70-80$ & $80-90$ & $90-98$ & & & & \\
\hline 1. Routine tasks & 0.13 & 0.39 & 0.39 & 0.76 & 2.46 & 3.36 & 3.22 \\
\hline 2. Non-routine tasks & 0.15 & 0.44 & 0.45 & 0.99 & 0.81 & 1.85 & 1.80 \\
\hline 3. All tasks & 0.28 & 0.87 & 0.88 & 1.75 & 3.27 & 5.29 & 5.02 \\
\hline Actual $\Delta$ college emp. & 5.74 & 4.27 & 2.56 & 6.83 & 6.83 & 12.57 & 6.83 \\
\hline
\end{tabular}

C. $100 \times$ Annual shifts in log (College/Non-College) demand

\begin{tabular}{|c|c|c|c|c|c|c|c|}
\hline \multirow[b]{3}{*}{ Shift measure } & \multicolumn{4}{|c|}{ Extensive margin } & \multirow{3}{*}{$\begin{array}{c}\begin{array}{c}\text { Intensive } \\
\text { Margin }\end{array} \\
80-98 \\
\end{array}$} & \multicolumn{2}{|c|}{ Sum } \\
\hline & & IPA Dat & & CPS Data & & & \\
\hline & $70-80$ & $80-90$ & $90-98$ & $80-98$ & & $70-98$ & $80-98$ \\
\hline $\begin{array}{c}\text { C.E. S. estimated demand } \\
\text { shift using } \sigma=1.4\end{array}$ & 3.26 & 4.60 & 2.09 & 6.69 & 6.69 & 9.95 & 6.69 \\
\hline Shift implied by task $\Delta^{\prime} s$ & 0.22 & 0.51 & 0.45 & 1.01 & 1.85 & 2.86 & 2.77 \\
\hline
\end{tabular}

Coefficients for fixed coefficient demand shifts calcuations are estimated from a regression of occupational college employment shares on DOT means using the 1970 Census. Changes in DOT skill measures predicted by computerization are from Tables 6 and 7 ('extensive margin') and Table 9 ('intensive margin'). Observed change in college employment (in FTEs) are estimated from Census 1970, Census 1980, Morg 1980, Morg 1990, Feb. 1990, and Morg 1998 samples for all employed workers. Constant Elasticity of Substitution estimates of changes in log(college/non-college) relative demand is based on Autor, Katz, and Krueger (1998) Table 2, updated to 1998 using CPS Morg 1998 sample. 


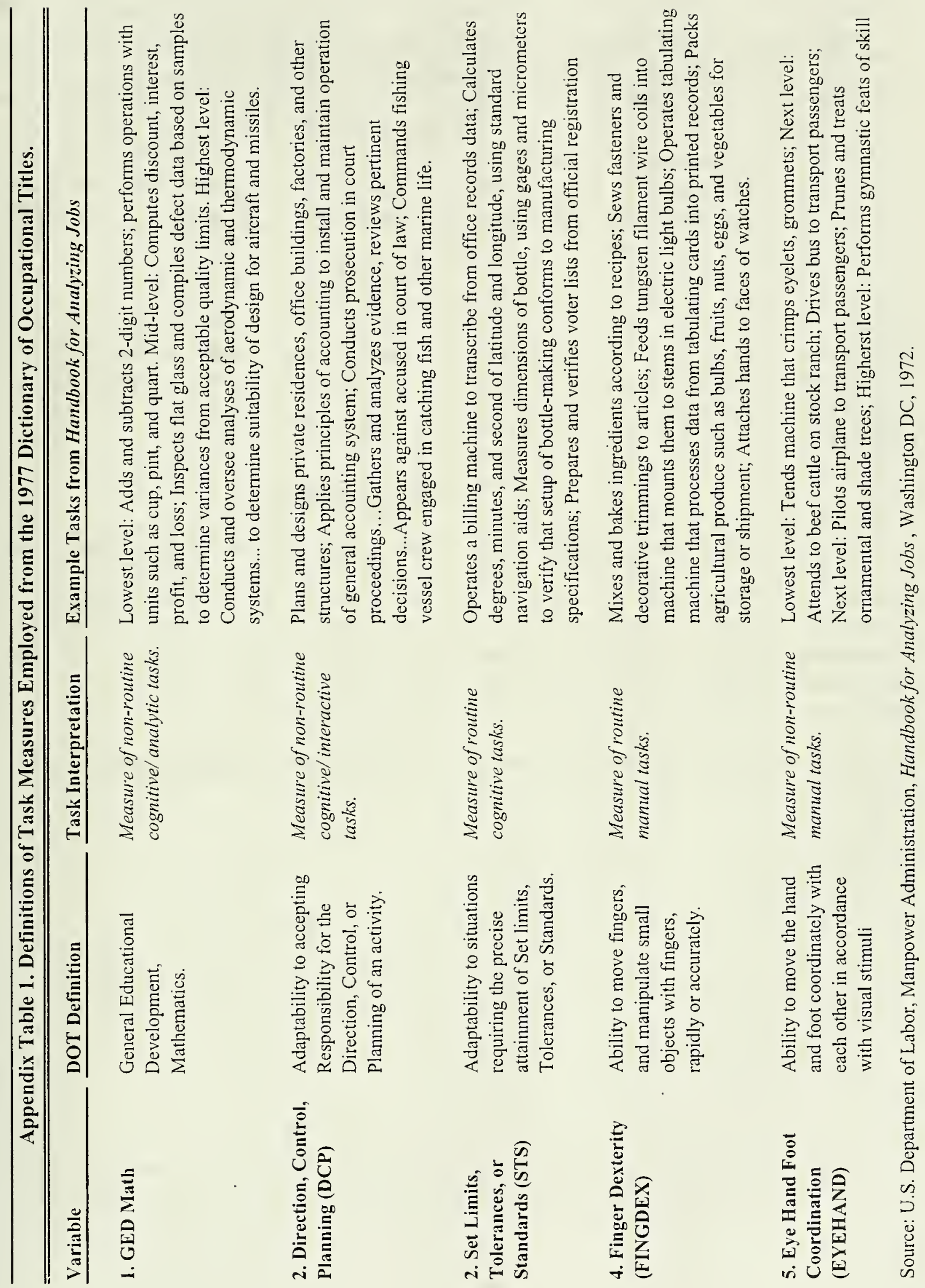




\begin{tabular}{l}
$\begin{array}{l}\text { Appendix Table 2: Means of Dictionary of Occupational Titles Job Content Measures Overall } \\
\text { and by Education Group at Mid-Point of } 1960-1998 \text { Sample. }\end{array}$ \\
\hline \hline
\end{tabular}

\section{Task Measure}

\begin{tabular}{|c|c|c|c|c|}
\hline $\begin{array}{l}\text { 1. Non-Routine } \\
\text { Cognitive/ } \\
\text { Analytic }\end{array}$ & $\begin{array}{l}\text { 2. Non-Routine } \\
\text { Cognitive/ } \\
\text { Interactive }\end{array}$ & $\begin{array}{l}\text { 3. Routine } \\
\text { Cognitive }\end{array}$ & $\begin{array}{c}\text { 4. Routine } \\
\text { Manual }\end{array}$ & $\begin{array}{l}\text { 5. Non-Routine } \\
\text { Manual }\end{array}$ \\
\hline & & A. Overall & & \\
\hline 3.76 & 2.46 & 4.61 & 3.90 & 1.24 \\
\hline 2.55 & 1.32 & 4.93 & 3.72 & 1.80 \\
\hline 3.34 & 1.75 & 5.30 & 4.09 & 1.26 \\
\hline 3.97 & 2.45 & 4.87 & 4.02 & 1.10 \\
\hline 5.36 & 4.76 & 2.86 & 3.57 & 0.87 \\
\hline
\end{tabular}

\section{B. Males and Females}

Overall

HS Dropouts

HS Graduates

Some College

College Plus

(1)

$\underline{\text { Male }} \underline{\text { Fem }} \underline{\text { Male }} \underline{\text { Fem }} \underline{\text { Male }} \underline{\text { Fem }} \underline{\text { Male }} \underline{\text { Fem }} \underline{\text { Male }} \underline{\text { Fem }}$

$\begin{array}{lllllllllll}\text { Overall } & 3.95 & 3.46 & 2.94 & 1.71 & 4.47 & 4.84 & 3.62 & 4.34 & 1.55 & 0.74 \\ \text { HS Dropouts } & 2.76 & 2.11 & 1.55 & 0.84 & 5.25 & 4.26 & 3.59 & 4.00 & 2.12 & 1.12 \\ \text { HS Graduates } & 3.45 & 3.20 & 2.17 & 1.20 & 5.14 & 5.50 & 3.69 & 4.61 & 1.77 & 0.60 \\ \text { Some College } & 4.07 & 3.82 & 2.97 & 1.68 & 4.38 & 5.58 & 3.62 & 4.61 & 1.42 & 0.62 \\ \text { College Plus } & 5.67 & 4.75 & 5.30 & 3.69 & 2.86 & 2.87 & 3.52 & 3.67 & 0.85 & 0.92\end{array}$

Sources: CPS MORG 1980, all employed workers ages 18 - 64 and Dictionary of Occupational Titles, 1977. 
Appendix Table 3. Estimates of the Relationship between Industry Computerization and Industry Task Input 1960 - 1998 Using Composite Task Measures.

Dependent Variables: $10 \times$ (Annual Change in Task Measure)

\begin{tabular}{|c|c|c|c|c|c|}
\hline Task Measure & Estimate & A. $1960-70$ & B. $1970-80$ & C. $1980-90$ & D. $1990-98$ \\
\hline 1. $\Delta$ Non-Routine & $\Delta$ Computer & 0.060 & -0.047 & 0.157 & 0.376 \\
\hline \multirow[t]{5}{*}{ Cognitive/ Analytic } & $1984-97$ & $(0.143)$ & $(0.127)$ & $(0.130)$ & $(0.134)$ \\
\hline & \multirow[t]{2}{*}{ Intercept } & 0.057 & 0.070 & 0.030 & 0.001 \\
\hline & & $(0.037)$ & $(0.034)$ & $(0.035)$ & $(0.037)$ \\
\hline & $\mathbf{R}^{2}$ & 0.00 & 0.00 & 0.01 & 0.05 \\
\hline & Mean Task $\Delta$ & 0.071 & 0.059 & 0.070 & 0.097 \\
\hline \multirow{6}{*}{$\begin{array}{l}\text { 2. } \Delta \text { Non-Routine } \\
\text { Cognitive/ }\end{array}$} & $\Delta$ Computer & 0.178 & 0.017 & 0.112 & 0.318 \\
\hline & $1984-97$ & $(0.118)$ & $(0.092)$ & $(0.120)$ & $(0.106)$ \\
\hline & \multirow[t]{2}{*}{ Intercept } & 0.012 & 0.051 & 0.047 & 0.006 \\
\hline & & $(0.030)$ & $(0.024)$ & $(0.032)$ & $(0.029)$ \\
\hline & $\mathbf{R}^{2}$ & 0.02 & 0.00 & 0.01 & 0.06 \\
\hline & Mean Task $\Delta$ & 0.054 & 0.056 & 0.075 & 0.087 \\
\hline 3. $\Delta$ Routine & $\Delta$ Computer & -0.031 & -0.239 & -0.106 & -0.181 \\
\hline \multirow[t]{5}{*}{ Cognitive } & $1984-97$ & $(0.075)$ & $(0.106)$ & $(0.097)$ & $(0.116)$ \\
\hline & \multirow[t]{2}{*}{ Intercept } & 0.022 & 0.025 & -0.030 & -0.039 \\
\hline & & $(0.019)$ & $(0.028)$ & $(0.026)$ & $(0.032)$ \\
\hline & $\mathbf{R}^{2}$ & 0.00 & 0.04 & 0.01 & 0.02 \\
\hline & Mean Task $\Delta$ & 0.015 & -0.034 & -0.060 & -0.086 \\
\hline \multirow[t]{6}{*}{ 4. $\Delta$ Routine Manual } & $\Delta$ Computer & 0.101 & -0.390 & -0.321 & -0.341 \\
\hline & $1984-97$ & $(0.102)$ & $(0.121)$ & $(0.130)$ & $(0.113)$ \\
\hline & \multirow[t]{2}{*}{ Intercept } & 0.016 & 0.040 & -0.002 & -0.007 \\
\hline & & $(0.026)$ & $(0.032)$ & $(0.035)$ & $(0.031)$ \\
\hline & $\mathbf{R}^{2}$ & 0.01 & 0.07 & 0.04 & 0.06 \\
\hline & Mean Task $\Delta$ & 0.040 & -0.010 & -0.083 & -0.095 \\
\hline \multirow{6}{*}{$\begin{array}{l}\text { 5. } \Delta \text { Non-Routine } \\
\text { Manual }\end{array}$} & $\Delta$ Computer & -0.027 & 0.004 & 0.138 & 0.274 \\
\hline & $1984-97$ & $(0.057)$ & $(0.090)$ & $(0.093)$ & $(0.075)$ \\
\hline & \multirow[t]{2}{*}{ Intercept } & -0.008 & 0.004 & -0.034 & -0.056 \\
\hline & & $(0.015)$ & $(0.024)$ & $(0.025)$ & $(0.021)$ \\
\hline & $\mathbf{R}^{2}$ & 0.00 & 0.00 & 0.02 & 0.09 \\
\hline & Mean Task $\Delta$ & -0.014 & 0.005 & 0.001 & 0.014 \\
\hline
\end{tabular}

$n$ is 140 consistent CIC industries. Standard errors are in parentheses. See Table Notes to Table 5 for details on estimation. See Data Appendix for details on construction of composite variables. 
Appendix Table 4. OLS Estimates of the Impact of Industry Computerization on Industry

Task Input by Education Group, 1980 - 98.

Dependent variable: $10 \times$ (Annualized Change in Task Measure)

Task Measure

\begin{tabular}{|c|c|c|c|c|}
\hline $\begin{array}{l}\text { 1. } \Delta \text { Non- } \\
\text { Routine } \\
\text { Cognitive/ } \\
\text { Analytic }\end{array}$ & $\begin{array}{l}\text { 2. } \Delta \text { Non- } \\
\text { Routine } \\
\text { Cognitive/ } \\
\text { Interactive }\end{array}$ & $\begin{array}{l}\text { 3. } \Delta \text { Routine } \\
\text { Cognitive }\end{array}$ & $\begin{array}{c}\text { 4. } \Delta \text { Routine } \\
\text { Manual }\end{array}$ & $\begin{array}{l}\text { 5. } \Delta \text { Non- } \\
\text { Routine } \\
\text { Manual }\end{array}$ \\
\hline
\end{tabular}

A. High School Dropouts

$\begin{array}{lccccc}\Delta \text { Computer } & 0.066 & 0.682 & -0.522 & -0.185 & -0.185 \\ \text { Use '84-'97 } & (0.215) & (0.476) & (0.559) & (0.162) & (0.150) \\ \text { Intercept } & -0.076 & -0.201 & 0.068 & 0.014 & 0.015 \\ & (0.045) & (0.099) & (0.117) & (0.034) & (0.031) \\ \text { Mean } \Delta & -0.063 & -0.068 & -0.034 & -0.022 & -0.021 \\ \mathbf{R}^{2} & 0.001 & 0.015 & 0.006 & 0.010 & 0.011\end{array}$

B. Some College

$\begin{array}{lccccc}\Delta \text { Computer } & 0.210 & 0.748 & -1.433 & -0.649 & -0.044 \\ \text { Use '84-'97 } & (0.161) & (0.281) & (0.369) & (0.152) & (0.107) \\ \text { Intercept } & -0.052 & -0.046 & 0.101 & 0.032 & 0.008 \\ & (0.034) & (0.058) & (0.077) & (0.032) & (0.022) \\ \text { Mean } \Delta & -0.011 & 0.100 & -0.178 & -0.095 & -0.001 \\ \mathbf{R}^{2} & 0.012 & 0.049 & 0.099 & 0.117 & 0.001\end{array}$

\section{College Graduates}

$\begin{array}{lccccc}\Delta \text { Computer } & -0.035 & 0.496 & 0.395 & -0.154 & 0.254 \\ \text { Use '84-'97 } & (0.176) & (0.388) & (0.396) & (0.135) & (0.125) \\ \text { Intercept } & 0.000 & -0.009 & -0.160 & -0.007 & -0.059 \\ & (0.037) & (0.081) & (0.083) & (0.028) & (0.026) \\ \text { Mean } \Delta & -0.007 & 0.088 & -0.083 & -0.037 & -0.010 \\ \mathbf{R}^{2} & 0.000 & 0.012 & 0.007 & 0.009 & 0.029\end{array}$

Standard errors are in parentheses. $n$ in panels A, B and C is 139,140 , and 139 consistent industries respectively. Industries that did not have employment in the relevant educational category in both 1980 and 1998 were excluded. Data sources are CPS MORG 1980 and 1998 and DOT 77 job task measures. Estimates are weighted by mean industry share of total employment (in FTEs) in 1980 and 1988.

Computer use is measured as ten times the change in industry computer use frequency from the 1984 and 1997 CPS (weighted mean 0.198). 


Date Due 


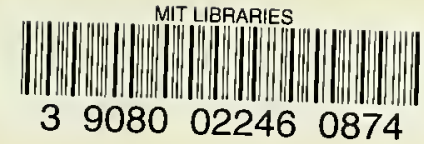


